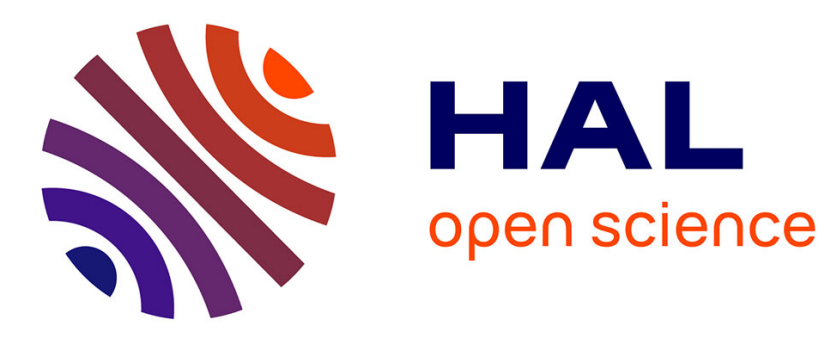

\title{
(Partially) Free choice of alternatives
}

Anamaria Falaus

\section{To cite this version:}

Anamaria Falaus. (Partially) Free choice of alternatives. Linguistics and Philosophy, 2014, 37 (2), pp.121-173. 10.1007/s10988-014-9146-8 . hal-01133698

\section{HAL Id: hal-01133698 \\ https://hal.science/hal-01133698}

Submitted on 25 Mar 2015

HAL is a multi-disciplinary open access archive for the deposit and dissemination of scientific research documents, whether they are published or not. The documents may come from teaching and research institutions in France or abroad, or from public or private research centers.
L'archive ouverte pluridisciplinaire HAL, est destinée au dépôt et à la diffusion de documents scientifiques de niveau recherche, publiés ou non, émanant des établissements d'enseignement et de recherche français ou étrangers, des laboratoires publics ou privés. 


\title{
(Partially) Free Choice of Alternatives
}

\author{
Anamaria Fălăuş
}

Pre-final version

\begin{abstract}
This paper contributes to the semantic typology of dependent indefinites, by accounting for the distribution and interpretation of the Romanian indefinite vreun. It is shown that its occurrences are restricted to negative polarity and a subset of modal contexts. More specifically, the study of its behavior in intensional environments reveals that vreun is systematically incompatible with non-epistemic operators, a restriction we capture by proposing a novel empirical generalization ('the epistemic constraint'). To account for the observed pattern, we adopt the unitary approach to polarity in Chierchia $(2006,2013)$ and derive the properties of vreun from its obligatory association with alternatives. Its distributional restrictions are argued to follow from the interplay between the types of alternatives it activates (scalar and subdomain alternatives), the way these alternatives are factored into meaning (via an independently motivated mechanism of exhaustification) and the lexical semantics of the operators in the context of occurrence. We propose that the epistemic constraint arises from the lexicalization of an inference (anti-total variation) that non-epistemic operators can never satisfy.
\end{abstract}

Keywords: polarity sensitivity, epistemic indefinites, free choice, alternatives, exhaustification 


\section{Introducing the Romanian determiner vreun}

\subsection{Background}

This paper focuses on the Romanian determiner vreun, whose distribution was shown by Farkas (2002) to pose a challenge to current theories of semantically dependent indefinites. Morphologically, vreun (and its feminine form vreo) is a complex variant of the standard indefinite article un (masculine)/o (feminine), combined with the morpheme vre- (from the Latin verb volere 'want'), which occurs with singular countable nouns. As illustrated by the ungrammaticality of the episodic sentence in (1), vreun has a restricted distribution, a property that sets it apart from the indefinite article form on which it builds:

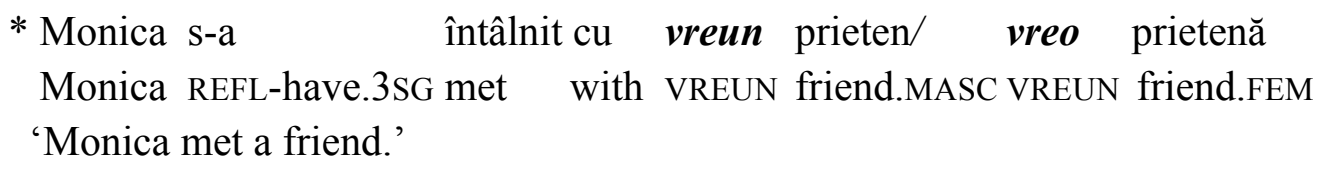

Exclusion from episodic sentences is typically assumed to be the hallmark of polarity sensitive, or more generally, dependent indefinites. ${ }^{1}$ A common strategy in the literature on polarity sensitive items consists in trying to identify licensing conditions, i.e. subsume their contexts of occurrence under some common description. Among other things, this strategy led to Ladusaw's generalization on the distribution of negative polarity items (NPIs), restricted to downward-entailing contexts (1979); or to the long-standing observation that free choice items (FCIs) are sensitive to modality (e.g. Vendler 1967). Licensing conditions are inherently descriptive, but they set the stage for an explanatory account for the phenomenon of polarity.

In line with this tradition, the first goal of the present study is to provide an accurate description of the contexts of occurrence of vreun. In doing so, we build on the account in Farkas $(2002,2006)$, which to my knowledge constitutes the only detailed study of vreun in the literature. We refine the empirical picture, by further probing two environments Farkas mentions, namely modal and attitude contexts. This brings out distributional contrasts previously overlooked, which I subsume under a novel empirical generalization ('the epistemic constraint'). The outcome is that vreun occurs in the scope of downward-entailing and non-factive epistemic operators, a pattern that sets vreun apart from other dependent indefinites documented to date. This empirical investigation contributes to a more general research program that aims to identify and explain the possible parameters of variation among (dependent) indefinites (see Aloni 2007; Aloni and Port 2010; Aloni and van Rooij 2007; AlonsoOvalle and Menéndez-Benito 2008, 2010; Chierchia 2006, 2013a; Condoravdi 2005;

\footnotetext{
${ }^{1}$ I use the terms 'polarity sensitive' and 'dependent indefinite' interchangeably, to refer to indefinites that are excluded from episodic sentences like (1).
} 
Dayal 1998, 2004; Farkas 2002, 2006; Giannakidou 1997, 2011; Haspelmath 1997; Jayez and Tovena 2006, 2007; Kratzer and Shimoyama 2002; Zamparelli 2007).

The second goal of this study is to provide an explanatory account of vreun, which derives its behavior from its meaning and the nature of semantic composition, without making reference to any licensing operators (be they downward-entailing or epistemic). To this end, adopting the framework in Chierchia (2006, 2013a,b), I develop an alternative-based account that captures its distribution, while providing ways to situate vreun in a broader typology of polarity sensitive indefinites. We analyze vreun as an indefinite with obligatorily active alternatives and show that its (un)grammaticality is the direct consequence of the interplay between its alternativetriggering meaning and the semantic properties of the embedding operator. More specifically, we will demonstrate that the alternatives activated by vreun can only be successfully factored into meaning in the presence of a downward-entailing or modal operator. The restriction to epistemic contexts is derived by positing a further requirement on the set of alternatives activated by vreun, which we argue to conflict with the lexical meaning of non-epistemic operators.

The discussion is organized as follows: in the rest of this section, we survey the distribution of vreun, drawing on the generalizations and account in Farkas (2002, 2006). In section 2 , we turn to a closer examination of the behavior of vreun in modal and attitude contexts, which we characterize by proposing a new empirical generalization ('the epistemic constraint'). Section 3 introduces the main assumptions underlying the alternative-based approach to polarity adopted in this paper (due to Chierchia 2013a,b). Section 4 derives the distribution of vreun, focusing on its restriction to epistemic contexts, which is argued to follow from constraints on the alternatives it activates and the semantics of the modal operators vreun interacts with. Section 5 summarizes and discusses some open issues for future research.

\subsection{A previous account: Farkas $(2002,2006)$}

We start our study of vreun ${ }^{2}$ by introducing the data and account in Farkas (2002, 2006), which constitute the point of departure of the present study.

The properties of the Romanian determiner vreun are first discussed in Farkas (2002), which carefully examines its distribution and points out the difficulty in formulating the underlying generalization(s). The first important descriptive observation is that vreun clearly does the work of a weak negative polarity item in Romanian, like English any or ever. The following examples ${ }^{3}$ show that the determiner vreun can be used in interrogatives (2), antecedents of conditionals (3) and restrictors of universal quantifiers (4), all very common NPI-licensing environments:

\footnotetext{
${ }^{2}$ I restrict the discussion to DPs introduced by vreun, but there is another morphologically related item vreodată (vre + odată 'once') 'ever' to which the analysis developed here can be extended. There is also a partitive use of vreun, mentioned in Farkas (2002), which I briefly discuss in section 2.5. The judgments reported here have been tested with around 30 native speakers.

${ }^{3}$ All examples in section 1.2 are taken from Farkas (2002), with glosses slightly modified to match the rest of the examples in this paper.
} 
(2) Ai văzut vreun ţigan fericit?

have.2SG seen VREUN gypsy happy

'Have you seen any happy gypsy?'

(3) Dacă găseşti vreo carte despre asta, cumpără-mi-o.

if find.2SG VREUN book about this buy-me.DAT-it

'If you find any book about this, buy it for me.'

(4) Fiecare fată care a dansat cu vreun student va fi chemată la direcţiune. every girl who has danced with VREUN student will be called to office

'Every girl who danced with any student will be called to the principal's office.'

In all these sentences, vreun has a meaning similar to polarity sensitive any. Furthermore, it can occur in the scope of negative operators:

a. A plecatfără să vorbească cu vreun profesor. has left without SUBJ speak with VREUN teacher '(S)he left without speaking to any teacher.'

b. $N u$ cunosc vreun medicament care să-1 ajute. NEG know.1SG VREUN medicine that SUBJ-him help 'I don't know of any medicine that can help him.'

Furthermore, like NPIs, vreun needs to be in the immediate scope of its licensor, a restriction that is responsible for its ungrammaticality in (6):
*Vreun student $n u$ a picat. VREUN student NEG has failed
'Any student didn't fail./No student failed.'

These facts suggest that vreun is subject to the same distributional constraints as NPIs. However, Farkas points out two facts indicating that the behavior of vreun doesn't entirely match that of NPIs: (i) restrictions on its use in negative sentences and (ii) occurrence in non-negative polarity contexts. First, unlike standard NPIs, vreun isn't always licensed by clause-mate sentential negation. The negative concord item niciun is used in negative sentences, rather than vreun, as illustrated in (7): ${ }^{4}$

$N u$ am *vreo prietenă/ $/$ nicio prietenă la Utrecht.
NEG have.1SG VREUN friend no friend in Utrecht
'I don't have any friend in Utrecht.'

\footnotetext{
${ }^{4}$ We find a reverse pattern in the case of non-local negation, which typically doesn't license negative concord items. As a result, vreun is acceptable in the scope of long-distance sentential negation. On the distribution of negative concord items in Romanian, see e.g. Fălăuş (2009) and Iordăchioaia (2009).
} 
The determiner niciun constitutes the default option in the local scope of sentential negation, but it does not entirely preclude the use of vreun, as exemplified above in (5b). The conditions governing the choice between vreun and niciun are not clear, but in contexts where they are both possible, such as (5), vreun seems to make a less categorical statement. More precisely, "vreun is natural in the presence of a clausemate negation in examples [...] where it is less likely that the truth of the statement can be checked by verifying all relevant values" (Farkas 2002:138), e.g. the entire set of possible medicines in (5b). Without getting into further details for the time being, let us conclude that the interaction of vreun with sentential negation is affected by the availability of negative concord items in Romanian.

A second set of facts not captured by characterizing vreun as an NPI is its occurrence in the non-negative polarity contexts in (8)-(9):

Din când în când trenul se oprea în vreo haltă și câte from when in when train-the REFL stop.IMPF.3SG in VREUN station and DIST un navetist deschidea un ochi.

a commuter opened an eye

'From time to time, the train would stop in some station and a commuter would open an eye.'

(9) a. E posibil ca Maria să se fi întâlnit cu vreun prieten be.3SG possible that Maria SUBJ REFL BE met with VREUN friend şi să fi rămas cu el în oraş.

and SUBJ BE remained with him in town

'It is possible that Maria met some friend and stayed with him in town.'

b. Poate că şi-a cumpărat vreo carte despre Utrecht.

perhaps that her.DAT-has bought VREUN book about Utrecht.

'Perhaps she bought herself some book about Utrecht.'

In (8), vreun is licensed by the so-called frequentative imperfective, which refers to a series of train-stopping events. The use of vreun stresses the random pairing between train-stopping situations and stations. In (9), vreun occurs in the scope of an epistemic modal operator and conveys the speaker's ignorance with respect to the referent of the vreun-DP. Crucially, none of these contexts license NPIs, as also attested by the fact that in English some or other would have to be used instead of any. From a crosslinguistic perspective, the occurrence of an item with NPI-like properties in nonnegative polarity environments is expected, as it constitutes a very common behavior for NPIs across languages (see e.g. Haspelmath 1997). However, unlike NPIs that double as FCIs and thus occur in various modal(ized) contexts (e.g. any), vreun is excluded from generic sentences, imperatives or the scope of the verb want:

$$
\begin{aligned}
& \text { (10) *Vreun lup mănâncă carne. } \\
& \text { VREUN wolf eats meat } \\
& \text { 'A wolf eats meat.' } \\
& \text { (11) *Ia vreun măr! }
\end{aligned}
$$


take.IMPV.2SG VREUN apple

'Take an apple!'

*Vreau să cumpăr vreo carte despre Olanda.

want.1SG SUBJ buy VREUN book about Holland

'I want to buy a book about Holland.'

These facts illustrate the challenge raised by the distribution of vreun: it resembles other polarity items in requiring some kind of licensor, but the set of licensing operators doesn't fall within the categories familiar from the study of other dependent indefinites. A proper account of vreun therefore needs to explain (i) why vreun has a limited distribution; (ii) why vreun is licensed in precisely the environments where we find it and only there; and (iii) the difference between vreun and other dependent indefinites in Romanian (e.g. FCIs orice or un oarecare, negative concord niciun).

Farkas (2006) provides answers to these questions, shedding light on the data discussed so far and situating vreun with respect to other dependent indefinites in Romanian. ${ }^{5}$ More precisely, Farkas argues that vreun is an obligatorily existential element (i.e. the variable it introduces has to be bound or has to agree with an existential quantifier), which requires the existence of a set of alternatives that count as equal. This is common to all occurrences of vreun. Depending on the alternatives involved and the requirement imposed on these alternatives, the uses of vreun fall under two categories. On the one hand, like NPIs and FCIs, vreun may denote a maximal set of alternatives that verify the expression in which the item occurs. On this use, which characterizes its occurrences in negative polarity contexts (such as (2)(5)), vreun is called an undifferentiated choice item. More formally, its interpretation involves a maximal set of mutually exclusive verifying alternatives. Alternatives are defined as assignment function-situation pairs and differ in the value assigned to a particular variable. The alternatives associated with vreun are maximal in that they include all possible values of the relevant variable (within the limits of salient contextual restrictions). The mutual exclusivity requirement ensures that each alternative in the relevant set is different from all the others, with respect to the values assigned to both individual and situation variables. The fact that alternatives are undifferentiated means that the choice among them is free: whichever alternative is chosen, the expression where vreun occurs is verified. For example, in the ifantecedent in (3), vreo carte denotes a maximal set of mutually exclusive alternatives involving different situations and different books in them, one such alternative for each possible book. The conditional then says that each larger possible situation in which the addressee finds a book is such that the addressee should buy that book. Which book is chosen for which situation is irrelevant; the only requirement imposed

\footnotetext{
${ }^{5}$ Farkas (2002) has mainly a descriptive goal, aiming to characterize the distribution of vreun and to identify its distinctive features with respect to other indefinites. Although this first paper on vreun contains some of the main ingredients of the analysis (e.g. the hypothesis that vreun is an obligatorily existential element, whose semantics makes reference to a set of alternatives), it is Farkas (2006) that provides a more detailed formal treatment of vreun. For reasons of space, I omit the presentation of the analysis in Farkas (2002) and focus on the more articulated version in Farkas (2006).
} 
by vreun is that there be one verifying alternative for each situation that satisfies the antecedent.

On the other hand, vreun can be used as a random choice item, in contexts such as (8) and (9) above, where undifferentiated choice items (e.g. NPIs and FCIs) are not possible (as the context could not satisfy the requirements imposed on the $i$ alternatives). Random choice items also make reference to a set of alternatives that count as equal, but they differ from the alternatives involved in the interpretation of undifferentiated choice items in two respects. First, undifferentiated choice items require the set of alternatives to be maximal, i.e. to involve all possible values, whereas the individual variable of a random choice indefinite does not have to exhaust the domain of possibilities. Second, random choice items must allow for the possibility that there be no verifying value for the indefinite. In (8) for instance, there are situations where the train does not stop and consequently, there is no value for the vreun phrase. Similarly in (9), the use of the epistemic modal is compatible with situations where Maria met no friend or no book about Utrecht is bought.

Taking stock, Farkas lays out the main properties of vreun and identifies the challenges they raise. On the account she proposes, there are two different uses of vreun, whose common thread is the reference to a set of alternatives. The context has to satisfy the requirements imposed by the use of an undifferentiated choice item (maximal mutually exclusive verifying alternatives) or those imposed by a random choice item (uncertain existence of verifying values). If neither can be done, as for example in episodic sentences, vreun is ruled out. For a formal implementation of the account sketched above and for details on how it rules out the use of vreun in environments such as those in (10)-(12) above, as well as the differences and similarities with other Romanian indefinites, the reader is referred to Farkas (2002, 2006). For our present purposes, this informal presentation of the analysis suffices to establish the main characteristics of vreun and sets the basis for the account to be developed in this paper. As we will see, the intuition that vreun is an existential element, whose distribution is restricted to two different sets of environments, as well as the idea that its semantics makes reference to alternatives, will be preserved. But first, I would like to complete the empirical picture outlined so far by further examining the behavior of vreun in two sets of non-negative polarity contexts, namely modals and attitude verbs. This will enable us to refine the generalizations introduced above, leading to a better understanding of the issues raised by vreun.

\section{The epistemic constraint}

This section shows that the distribution of vreun in modal and attitude contexts is subject to further restrictions, which I capture by proposing a novel empirical generalization, 'the epistemic constraint'. 


\subsection{The basic distinction}

In the previous section, we have seen that in addition to its NPI use, vreun occurs in non-negative polarity environments, such as (9), repeated below:

(9) E posibil ca Maria să se fi întâlnit cu vreun prieten be.3SG possible that Maria SUBJ REFL BE met with VREUN friend şi să fi rămas cu el în oraş.

and SUBJ BE remained with him in town

'It is possible that Maria met some friend and stayed with him in town.'

In (9), vreun takes scope under the modal operator 'it's possible'; the sentence conveys that Maria might have met a friend, the speaker doesn't know which friend, and she might have stayed with him in town. In order to understand this use of vreun, it will be useful to consider indefinites that trigger a similar ignorance (or indifference) reading, such as the closely related Romanian indefinite un NP oarecare (Săvescu-Ciucivara 2007:211):

(13) Maria poate să rezolve o problemă oarecare.

Maria can SUBJ solve.3SG a problem OARECARE

a. 'There is a certain problem that Maria can solve, the speaker doesn't know/care which problem it is.'

b. 'No matter what problem Maria is faced with, she is able to solve it.'

Both vreun and un NP oarecare are existential elements, occurring in modal contexts, and signaling that the speaker is unable (or unwilling) to identify the individual that satisfies the modal claim. Indefinites that convey information about the speaker's epistemic state are often referred to as epistemic or modal indefinites and have received a lot of attention in the last decade (e.g. Aloni and Port 2010; Alonso-Ovalle and Menéndez-Benito 2008, 2010; Chierchia 2006, 2013a; Farkas 2002, 2006; Giannakidou and Quer 2012; Jayez and Tovena 2006, 2007; Kratzer and Shimoyama 2002, among others). One of the common properties of these indefinites is their incompatibility with a continuation that would identify a referent for the indefinite phrase, i.e. the sentences in (9) and (13) couldn't be felicitously followed by something like namely Paul. ${ }^{6}$ I will employ the term epistemic indefinite to refer to the use of vreun in non-negative polarity contexts.

In the following, I argue that modals and attitude predicates provide crucial insights into the constraints governing the behavior of vreun as an epistemic indefinite. To show this, we examine previously overlooked contrasts in its distribution. More concretely, the contrast in (14)-(15) indicates restrictions on its occurrence in modal environments:

\footnotetext{
${ }^{6}$ The namely test was initially used for free relatives, which also have an ignorance or an indifference reading, see e.g., Dayal (1997), von Fintel (2000), Rawlins (2008). For a comparison between wh-ever relatives and free choice and epistemic indefinites, see Dayal $(2009,2013)$.
} 
(14) $\mathrm{Cu}$ numele lui, trebuie să fie vreun aristocrat. with name-the his must SUBJ be.3SG VREUN aristocrat 'Given his name, he must be some aristocrat.'

(15) *Trebuie să mă înscriu la vreun curs până mâine. must SUBJ REFL register.1SG at VREUN class until tomorrow 'I have to register for a class by tomorrow.'

Likewise, vreun is possible under some attitude verbs (hope), but not others (want):

-Sper /*Vreau să găsesc vreun cadou pentru sora mea. hope.1SG want.1SG SUBJ find.1SG VREUN present for sister-the my 'I hope/want to find some present for my sister.'

The first goal is to identify the factor(s) responsible for the contrasts in (14)-(16), which are unexpected given the types of dependent indefinites attested in the literature. The examples above suggest that vreun occurs in a subset of intensional environments, so our first task in this connection is to find a uniform way to characterize the relevant environments. As discussed in section 1.2, vreun occurs in contexts that are 'hypothetical', where "the choice of vreun over the ordinary indefinite $[. .$.$] stresses the uncertainty of the existence of a verifying value in the$ world of evaluation" (Farkas 2006:90). Refining this observation, I argue that the distribution of vreun in non-negative polarity contexts is captured by the following generalization:

\section{THE EPISTEMIC CONSTRAINT ${ }^{7}$}

The determiner vreun is licensed by obligatorily non-factive epistemic operators.

By 'obligatorily non-factive epistemic operators', I refer to operators that quantify over epistemic alternatives and whose semantics makes them incompatible with situations where the proposition $p$ embedded by the operator is established to be true. To put it differently, according to the epistemic constraint in (17), the epistemic alternatives must include both $p$-worlds and non $p$-worlds. This formulation seeks to capture the intuition that the uncertainty (concerning the truth of $p$ ) component is crucial for the acceptability of vreun. To make this concrete, let me demonstrate how

\footnotetext{
${ }^{7}$ In previous work, I offered a somewhat more abstract formulation of the epistemic constraint:

(i) Context of occurrence: Op [...vreun...]

Op $p$ entails that the speaker's epistemic alternatives include non $p$-worlds

However, the formulation in (i) obscures the fact that the epistemic constraint is a descriptive statement, which puts together a number of contexts of occurrence, but which ultimately has no explanatory value on its own. The formulation in (17) retains the empirical coverage of (i), but has a more clearly descriptive status.
} 
the epistemic constraint applies to vreun in the scope of modal operators (2.2 and 2.3) and attitude verbs (2.4).

\subsection{Presumptive mood}

The epistemic constraint is based on the intuition that vreun is restricted to environments that are hypothetical, where the speaker communicates she is not in a position to rule out completely the possibility that the proposition containing vreun is false. The context that shows in a straightforward way the role of this 'uncertainty' component is the presumptive mood - a 'specialized' mood for conveying hypotheses - which constitutes one of the prototypical contexts of occurrence for vreun. Morphologically, it presents different paradigms, following the pattern AUXILIARY MODAL (conditional/future/subjunctive) + BE + PARTICIPLE (present/past). Irimia (2010) investigates the properties of the presumptive mood, and the way it differs from its homonymous future/conditional constructs, arguing that presumptive forms are subject to distinct syntactic, pragmatic, and semantic constraints. The point that bears directly on our discussion is that presumptive forms are semantically very similar to epistemic modals, insofar as they have a meaning component of indirect evidentiality. This means that upon using the presumptive, the speaker makes a claim that a certain state of affairs might hold (or might have held) and signals that her claim is based on an indirect source of information (e.g. inference or hearsay). This implies that the speaker is not in a position to exclude that things might be (or have been) different. The construct that is most relevant for our present purposes is the socalled future2-based form, which always associates with inferences based on indirect evidence. The example in (18), taken from Irimia (2010), constitutes a typical context of use, where the fact that the lights are off is taken to be indirect evidence for the claim that someone might have gone to bed:

Luminile sunt stinse în apartamentul lor. S-or fi culcat. lights-the are off in apartment their SE-FUT2.3PL BE sleep.PAST.PRT $\approx$ 'The lights are off in their apartment. They might/must have gone to bed.'

The indirect evidentiality meaning associated with the presumptive form is not compatible with a proposition $p$ that is taken to be true. In other words, the speaker's epistemically accessible worlds have to include both $p$ - and non $p$-worlds. As a result, the presumptive can never be used in propositions established to hold, such as the direct evidence context in (19) or the complement of a factive verb like know (20):

\section{Watching by the window and seeing pouring rain:}

\#O fi plouând.

FUT2.3SG BE rain.1SG.PRST.PART

'It must be raining.'
*Ştiu
că $o i$
fi având
un virus în calculator
know.1SG that FUT2.1SG BE have.1SG.PRST.PART a virus in computer 
'I know I must have a virus in my computer.'

As predicted by the generalization in (17) above, which states that vreun is licensed by non-factive epistemic operators, the (inferential) presumptive plays a crucial role in the distribution of vreun:

(21) Context: The house has been turned upside down and the money is missing.

a. A intrat *vreun/ $/$ un hoţ. have.3SG entered VREUN a burglar

b. $O \quad f i$ intrat vreun hoţ.

FUT2.3SG BE enter.PAST.PART VREUN burglar

'A burglar might have got in.'

The intended interpretation of (21) is a hypothesis about the reason behind the mess in the house and the disappearance of the money, but despite this hypothetical meaning, clearly indicated by the context, vreun is ruled out in the episodic sentence in (21a). In contrast to this, the plain indefinite un hot 'a burglar' would be acceptable and would convey the intended ignorance effect concerning the identity of the burglar. If the indicative verbal form is replaced by the presumptive, vreun becomes acceptable (21b). This contrast is captured by the epistemic constraint in (17): in (21a), there is no operator that could license vreun, whereas in (21b), the use of the presumptive arguably supplies a non-factive epistemic licensor, which makes vreun acceptable.

These facts demonstrate the tight connection between vreun and the hypothetical meaning conveyed by the presumptive, a connection which makes the (inferential) presumptive an extremely frequent context of use for vreun. ${ }^{8}$ The contrast in (21) further shows that vreun is ruled out in episodic sentences (as already illustrated in (1) above) and that context is not sufficient to license vreun, even in cases where the intended hypothetical reading is easily available.

\subsection{Modal contexts}

The epistemic constraint in (17) also captures the distribution of vreun in a closely related set of environments, namely the scope of modals. Romanian has two modal auxiliaries, the possibility modal a putea and the necessity modal a trebui, which are used to express a wide range of modal meanings. The determiner vreun can occur under both these modals, but crucially, only when they are interpreted with respect to an epistemic modal base. For illustration, consider the following examples:

Se aud des sirene de ambulanţă, trebuie/poate să fie SE hear.3PL often sirens of ambulance must may SUBJ be.3SG

\footnotetext{
${ }^{8}$ Vreun is also possible under the hearsay presumptive, especially in combination with the hearsay evidential cică, but this use is much less frequent and may be subject to dialectal variation:

(i) Cică ar $\quad f i$ apărut vreun nou virus extrem de periculos. EVID.ADV COND.3SG BE appeared VREUN new virus extremely of dangerous '(I hear/They say) A new, extremely dangerous virus has appeared.'
} 
vreun spital prin zonă.

VREUN hospital in area

'One can often hear ambulance sirens, there must/may be a hospital nearby.'

*Trebuie să trimit vreun articol până mâine.

must SUBJ write.1SG VREUN article by tomorrow

'I must send a paper by tomorrow.'

${ }^{*} \mathrm{Ca}$ să ajungi în centru, poţi lua vreun autobuz.
that SUBJ get.2SG in center can.2SG take VREUN bus
'In order to get downtown, you can take a bus.'

Sentence (22) has an epistemic construal, both with the necessity modal and the possibility modal, and vreun is perfectly acceptable. In contrast to this, when the modal has a deontic (23) or teleological (24) construal, vreun cannot be used, even if the speaker is fully ignorant with respect to the referent of the vreun-phrase. The obvious source for this contrast lies in the kind of alternatives that are relevant for the interpretation of the modal operator - epistemic in (22) and non-epistemic (sets of obligations or goals) in (23)-(24). Adopting the theory of modality due to Kratzer (1981, 1991), the interpretation of (22) amounts to (universal or existential) quantification over the worlds in the epistemic modal base, which picks out worlds compatible with the available evidence (e.g. the frequent sound of sirens, the fact that ambulances typically head to hospitals). In contrast to this, the modal statements in (23)-(24) are interpreted with respect to a circumstantial modal base, in which the relevant worlds are determined by certain obligations, goals or desires. These examples show that the epistemic modal base plays a decisive role in the acceptability of vreun, corroborating the epistemic constraint proposed in (17).

Having confirmed the role of epistemic alternatives, we can now examine more carefully the role of non-factivity, the other factor present in the epistemic constraint. Recall that this component of the generalization in (17) seeks to capture the 'uncertainty' flavor that characterizes the environments where epistemic vreun is acceptable, i.e. the incompatibility with operators that establish the proposition containing vreun to hold. Epistemic modals generally fall under this pattern. More specifically, in addition to quantification over epistemically accessible worlds, the meaning of an epistemic modal has often been argued to involve an indirect evidentiality component (see von Fintel and Gillies 2010 for a recent discussion of this matter). Simplifying, epistemic modals are sensitive to the type of evidence that is relevant for the truth of $p$ : upon using an epistemic modal, the speaker is not only conveying something about her beliefs, ${ }^{9}$ but also that she only has indirect evidence for her claim. This leaves open the possibility that direct evidence eventually contradicts $p$. Arguments in favor of the presence of the evidential component come from situations where direct evidence conflicts with the use of an epistemic modal.

\footnotetext{
${ }^{9}$ According to the standard analysis of epistemic modals, we express possibilities on the basis of what is known (in the actual world). However, the behavior of embedded epistemic modals indicates that they are not necessarily knowledge-based, but rather they express compatibility with an epistemic agent's beliefs, or his information state (e.g. Hacquard 2006).
} 
The typical example involves perceptual evidence, e.g. upon looking at pouring rain, one cannot utter something like It must be raining. Direct evidence settles the truth of $p$, and conflicts with the indirectness signal carried by an epistemic modal. This in turn means that when the speaker chooses to make use of an epistemic modal, we are entitled to draw the inference that she is not in a position to make the non-modalized claim It is raining, i.e. she cannot rule out the possibility that the proposition does not hold. In other words, the speaker's epistemic alternatives include (possibly unlikely) non $p$-worlds, a property that proves crucial for the distribution of vreun, both for its use with modal auxiliaries and the presumptive mood. ${ }^{10}$

Interestingly, there are contexts where the uncertainty associated with indirect evidence does not seem to hold, as in (25), due to von Fintel and Gillies (2010):

(25) Chris has lost her ball, but she knows with full certainty that it is either in Box A or B or C. She says:

The ball is in A or in B or in C. It is not in A. It is not in B. So, it must be in C.

Romanian epistemic modals are no different in this respect, i.e. they can be used in contexts like (25). However, whenever the uncertainty is explicitly ruled out, vreun is deviant. To see this, consider the following example:

(26) We are playing cards. In order to win, I still need the ace of spades. However, by now all cards have been played and it is clear that the ace is not in the pile of cards on the table. So the only option is that one of the other players has it:

Asul trebuie să fie la *vreun $/ \sqrt{ }$ un jucător (şi poate fi oricare din ei). ${ }^{11}$ ace-the must SUBJ be.3SG at VREUN a player and could be any of them 'The ace must be with some/a player (and it could be any of them)'

The context makes it clear that one of the players has the ace, and although the speaker cannot identify the player in question, vreun cannot be used. Whenever the proposition embedded under the modal is established to hold, vreun is ruled out. However, most uses of epistemic modals differ from (25) and (26), insofar as the embedded proposition is typically not established to be true. As a result, non $p$-worlds are included among epistemic alternatives, i.e. the context is non-factive, a property that leads to the acceptability of vreun.

\footnotetext{
${ }^{10}$ Further evidence in favor of the non $p$-worlds component of epistemic modals comes from the following contrast (provided by an anonymous referee and attributed to Frank Veltman):

(i) The door is ringing. It must be the pizza deliverer. No - it's the mailman.

(ii) The door is ringing. It is the pizza deliverer. \#No - it's the mailman.

${ }^{11}$ As correctly noted by one of the referees, a possible issue arising in this context is the preference for a partitive indefinite (plain or epistemic). Since the set of possible values is very clear in the context, the default option used by speakers is a partitive indefinite like one of the players. The continuation in (26), and it could be any of the players is needed in order to make the use of a plain indefinite ( $a$ player) felicitous. However, despite the continuation, (non-partitive) vreun remains illicit in this context (for remarks on partitive vreun, see section 2.5).
} 
Summarizing, our discussion so far underlines the role of two factors in the distribution of vreun (i) epistemic alternatives and (ii) non-factivity (i.e. the existence of non $p$-worlds among the epistemic alternatives). I have argued that the epistemic constraint captures two tightly related contexts, both involving a component of indirect evidentiality - presumptive forms and epistemic modals. I now turn to attitude contexts, and show that they provide further support for the generalization in (17).

\subsection{Attitude contexts}

We have seen that the semantic properties of intensional operators embedding vreun provide the key to an adequate description of its restricted distribution. In addition to modals, one other context that is particularly relevant in this connection are attitude verbs. ${ }^{12}$ As expected in view of the previous discussion, we will be primarily concerned with the area of epistemic attitudes. Just like with modals, epistemic alternatives prove to be the crucial factor to which vreun is sensitive. This hypothesis is substantiated by the ungrammaticality of vreun under predicates whose interpretation does not involve epistemic alternatives, namely predicates referring to obligations, requests or suggestions, like the ones in (27):

$\begin{array}{lllll}\text { *Roxana } & m-a & \text { rugat/ } m i-a & \text { cerut/ } & m i-a \\ \text { Roxana me-have.3SG } & \text { asked me-have.3SG requested me-have.3SG } \\ \text { ordonat/ } m i-a & \text { sugerat să aduc vreun cadou. } \\ \text { ordered me-have.3SG } & \text { suggested SUBJ bring VREUN present } \\ \text { 'Roxana asked/requested/ordered/suggested to me to bring some present.' }\end{array}$

Let us then focus on attitude predicates involving quantification over epistemic alternatives. On the generalization proposed here, we expect vreun to be ruled out under operators whose complement proposition is established to be true. The systematic ungrammaticality of vreun in factive contexts shows that this is borne out:

*Ştiu $\quad / * A m \quad$ aflat că am vreun virus în calculator.

know.1SG have.1SG found-out that have.1SG VREUN virus in computer 'I know/found out that I have some virus in my computer.'

In contrast to this, vreun is perfectly acceptable under non-factive doxastic predicates:

$\begin{array}{llllll}\text { Cred }^{13} / & \text { Bănuiescl } & \text { Sunt convins/ Sunt sigur că } \\ \text { believe.1SG } & \text { suppose.1SG } & \text { am.1SG convinced am.1SG sure that } \\ \text { am } & \text { vreun virus in calculator. } & & & \\ \text { have.1SG } & \text { VREUN virus in computer }\end{array}$

12 To the best of my knowledge, most of the facts introduced in this section constitute novel observations. Farkas (2002) notes the exclusion of vreun from the scope of want and emotive factives, but does not discuss further attitude contexts.

${ }^{13}$ The verb a crede lit. 'to believe' is ambiguous between English to believe and to think. The verb a se gândi lit. 'to think' is less frequent and conveys a more hypothetical meaning, similar to suppose. 
'I think/suppose/I'm convinced/sure I have some virus in my computer.'

How do these attitude predicates line up with the epistemic constraint? Recall the case of necessity epistemic modals: when we use Must $p$ (on its epistemic construal), we assert that our epistemic alternatives are such that the proposition $p$ holds, but we also typically convey that the claim is based on indirect evidence and hence we are not in a strong enough position to completely rule out non $p$-worlds. Likewise, when we assert something like 'I think/suppose/assume $p$ ', we not only communicate that it is compatible with our beliefs that a certain state of affairs holds (denoted by the complement proposition $p$ ), but also that we cannot fully exclude non $p$-situations. Crucially, if the complement proposition is established to be true, the speaker cannot use think or suppose (she would use know or believe). For example, in the pouring rain context, the speaker cannot felicitously utter I think/suppose it is raining. We find a similar incompatibility with situations where $p$ is established to hold even for verbs like be convinced/sure, which once again, tend to be used in contexts where non $p$ might hold. What is important to notice, in this connection, is the relevance of the uncertainty component for the occurrence of vreun. Just like with epistemic modals, if $p$ is necessarily true, the embedding operators may sometimes be used, but vreun is ruled out. To see this, let us use the same context as in the case of epistemic modals:

(30) We are playing cards. In order to win, I need the ace of spades. However by now, all cards have been played and it is clear that the ace is not in the pile of cards on the table. So the only remaining option is that one of the other players has it. I might not have thought this before, but now:

Cred /Sunt convins că asul e la *vreun/S un jucător. believe.1SG am.1SG convinced that ace-the is at VREUN a player 'I believe (=know)/I am convinced that some/a player has the ace.'

Verbs like think/believe or be convinced are generally not used in contexts where the embedded proposition is established to hold. If we enforce such a context, however, we see that vreun is ruled out, a fact that I take to support the generalization in (17).

The epistemic constraint defines the set of licensing operators of vreun as 'obligatorily non-factive epistemic' operators. While the role of epistemic alternatives and non-factivity is clear in the distribution discussed so far, the 'obligatorily nonfactive' part hasn't yet been justified. Its role is to capture the contrast already mentioned in (16) above, namely that between want, which precludes the use of vreun in its complement (31), and hope, which allows it (32):

$$
\begin{aligned}
& \text { *Vreau să găsesc vreun cadou pentru sora mea. } \\
& \text { want.1SG SUBJ find.1SG VREUN present for sister-the my } \\
& \text { 'I want to find some present for my sister.' }
\end{aligned}
$$

Sper să găsesc vreun cadou pentru sora mea. hope.1SG SUBJ find.1SG VREUN present for sister-the my 'I hope to find some present for my sister.' 
This contrast is surprising: both want and hope are non-factive predicates interpreted with respect to a set of doxastic alternatives and expressing that the worlds in which the embedded proposition holds are ranked high with respect to the attitude holder's preferences (Heim 1992, von Fintel 1999). The two attitudes have a very similar semantics, but a non-uniform behavior with respect to the acceptability of vreun in their complement. The epistemic constraint, I argue, captures this contrast. To show this, I build on recent work on preference verbs, due to Scheffler (2008). More precisely, in discussing the semantics of preference verbs that allow V2 complements in Germanic, Scheffler identifies an epistemic component in the meaning of hope, which only makes it compatible with situations where the truth of the embedded proposition is not established, a property that want lacks. The contrast that is relevant for present purposes is given in $(33):^{14}$

(33) (To my students, in the middle of my class) I am teaching semantics...

a. $\quad \checkmark$...because I want to be teaching semantics $/ \checkmark$... and that is what I want.

b. \# ... because I hope to be teaching semantics/ \# ... and that is what I hope.

Using once again a context that establishes a certain fact to hold, we notice that while want is perfectly compatible with this situation (33a), hope is not (33b). The fact that the truth-value of $p$ is settled makes the use of hope infelicitous to refer to this fact, a restriction that does not apply to want. This shows that want does not entail that the epistemic agent countenances non p-worlds, whereas hope does. This is the conclusion reached in Scheffler (2008), who argues that hope implies that at the time of evaluation, the epistemic agent considers that both $p$ and non $p$ can hold. Of course, want can also be used in cases where both $p$ and non $p$ are considered possible, but the important point is that nothing in its meaning imposes the existence of non $p$-worlds among the doxastic alternatives, as made clear by its use in contexts like (33), where the complement proposition is established to hold. This, I argue, is the key difference between want and hope to which the distribution of vreun is sensitive. The epistemic constraint proposed in this paper captures this contrast, by making reference to 'obligatorily non-factive epistemic' operators.

\subsection{Further empirical issues}

Let us now take stock and review the main results of the discussion so far. The primary goal of this section was descriptive, and consisted in the identification of 'licensing constraints', i.e. the factors underlying the (non-)occurrence of the determiner vreun. I take the facts examined in this paper to indicate that the core distribution of vreun can be subsumed under two broad categories: (i) negative polarity environments and (ii) (a subset of) epistemic contexts.

\footnotetext{
${ }^{14}$ I am grateful to an anonymous referee for suggesting the use of complements over which the subject has control and for helping me clarify this part of the discussion.
} 
On the one hand, as already shown in Farkas (2002), in negative polarity contexts, vreun behaves like an NPI. More precisely, vreun occurs in a wide range of (arguably) downward-entailing contexts ${ }^{15}$ (see examples (2)-(5) in section 1.2). To this, we may add the fact that vreun is sensitive to intervention effects, a property of NPIs known since Linebarger (1980). In (34b) for example, conjunction has an intervening effect, rendering the sentence ungrammatical.

a. Mă indoiesc că Paul a obţinut vreun rezultat interesant. REFL.1SG doubt.1SG that Paul has obtained VREUN result interesting 'I doubt that Paul has obtained any interesting result.'

b. *Mă indoiesc că a obţinut date noi şi vreun rezultat interesant. REFL.1SG doubt.1SG that has obtained data new and VREUN result interesting 'I doubt that he has obtained new data and any interesting result.'

The only unexpected aspect of the behavior of vreun in negative polarity contexts is its interaction with sentential negation. More precisely, recall that its distribution in negative sentences is affected by the availability of the negative concord item niciun, which constitutes the default option (see the examples in (7)). There are however contexts where vreun easily co-occurs with sentential negation, namely sentences with negative concord indefinites, such as (35):
Nimeni nu a
avut vreo informaţie despre crimă.
Nobody NEG have.3SG had VREUN information about murder
'Nobody had any information on the murder.'

The reason for using vreun in (35), I assume, is that a sentence with two negative concord indefinites is ambiguous between a negative concord reading (with a single negation) and a double negation reading (where the two negations cancel each other out), as shown in Fălăuş (2009) and Iordăchioaia (2009). For example, if we replace vreo in (35) with nicio, the sentence becomes ambiguous between the negative concord reading we could paraphrase as 'It is not the case that anybody had any information on the murder' and a double negation reading equivalent to 'Everybody had (at least) some information on the murder'. The analysis of negative concord is not directly relevant to our discussion, the only important matter being that in order to avoid the ambiguity caused by the co-occurrence of several negative concord indefinites, whenever possible, vreun indefinites are used instead, yielding only the reading associated with negative concord. This indicates that vreun can occur in the direct scope of clause-mate sentential negation and is thus no different from other NPIs in this respect. The fact that its distribution is more restricted, as compared to

\footnotetext{
15 There are well-known issues arising with respect to the generalization that NPIs are licensed in downward-entailing contexts, which need not concern us here (see Zwarts 1998, von Fintel 1999, Guerzoni and Sharvit 2007, Gajewski 2011, Giannakidou 2011, Nicolae 2013). The only relevant observation at this point is the similarity between the distribution of vreun and that of other, more familiar, NPIs across languages.
} 
NPIs like any or ever, is closely related to the existence of negative concord items, used as the default option in this context. The data considered here, then, supports the generalization that vreun displays an NPI-behavior.

On the other hand, vreun occurs in the contexts subsumed by the epistemic constraint proposed in (17), which holds that vreun is licensed only by operators that are epistemic and whose semantics is incompatible with situations in which the complement proposition is established to be true. In this section, I have argued that this constraint provides a uniform characterization of the distribution of vreun in modal and attitude contexts, thus offering a better perspective on what an explanatory account of vreun needs to capture.

The epistemic constraint helps disentangle an otherwise puzzling data set, but does not cover all non-negative polarity uses of vreun. In particular, it does not apply to its occurrence in sentences involving frequentative imperfectives, noted by Farkas (2002), illustrated in (8), repeated below as (36):

(36) Din când în când trenul se oprea în vreo haltă și câte from when in when train.DEF REFL stop.IMPF.3SG in VREUN station and DIST un navetist deschidea un ochi.

a commuter opened an eye

'From time to time, the train would stop in some station and a commuter would open an eye.'

This environment doesn't fall under the epistemic constraint in any obvious way (and is not a negative polarity context either), but a proper discussion of how the account proposed in this paper extends to frequentative imperfectives must be left for another occasion.

To complete the description of the empirical properties of vreun, let me also note that the epistemic constraint does not apply to partitive vreun, which, as already mentioned in Farkas (2002), has a less restricted distribution than non-partitive vreun. More precisely, insofar as I can tell, it occurs in all contexts where non-partitive vreun can occur, but it is also acceptable in epistemic contexts where $p$ is established to hold, such as the modal statement in (37) (in the 'factive' context in (26) above):

(37) Asul trebuie să fie la vreunul din jucători. ace-the must SUBJ be.3SG at VREUN.DEF of players 'The ace must be with one of the players.'

Similar considerations apply to the scope of think or suppose, i.e. partitive vreun would be acceptable in (30) above. ${ }^{16}$ Furthermore, the following example shows that it can also be used in some deontic contexts:

\footnotetext{
${ }^{16}$ The speakers I have consulted reject partitive vreun in the scope of factive verbs like know or find out, but further investigation is needed before reaching firm conclusions on this matter.
} 
'To be eligible, the candidates must meet one of the conditions specified by the law.'

The properties of partitive vreun and the connection with its non-partitive counterpart need to be carefully investigated, but the facts in (37)-(38) suffice to establish that its distribution is not subject to the epistemic constraint. In this paper, I set aside the properties of partitive vreun and focus on the non-partitive determiner. ${ }^{17}$

Before proposing an account for the facts described above, a cross-linguistic remark. Putting aside the use of vreun in negative polarity contexts, we have seen that it resembles epistemic indefinites in occurring in modal contexts and conveying some form of uncertainty with respect to the referent. However, the paradigm we uncovered represents a more restricted case of semantic dependency, which to my knowledge has not been previously documented. The present focus on accurately describing, and accounting for, the properties of vreun prohibits an in-depth discussion of the typology of epistemic indefinites. Let me simply note that the restriction to epistemic contexts, in the sense discussed here, does not seem to characterize other dependent indefinites described in the literature. The difference becomes obvious once we consider their distribution in modal contexts. For example, nonveridical items like Greek kanenas (Giannakidou 1997, 2011) or epistemic indefinites like Spanish algún (Alonso-Ovalle and Menéndez-Benito 2008, 2010) share with vreun the property of occurring in both negative polarity and modal contexts. However, unlike vreun, they do not impose any restriction on the type of modal operator, as attested by their occurrence under deontic modals:
a. Prepi na episkeftis kanenan jatro. must.3SG SUBJ visit KANENAS doctor 'You should visit a doctor.'
b. Maria tiene que terminar algún artículo para mañana. Maria has COMP finish ALGUN article for tomorrow 'Maria has to finish some paper for tomorrow.'

Distribution-wise, the determiner that seems to come closest to vreun is French singular quelque, discussed in detail in work by Jayez and Tovena $(2006,2007) .{ }^{18} \mathrm{~A}$

\footnotetext{
${ }^{17}$ The distribution of any and partitive any is also different. However, whereas partitive vreun seems to have a wider distribution than its non-partitive counterpart, in the case of any, the partitive version has a more restricted distribution than the non-partitive one (see e.g. Dayal 2004, 2013).

${ }^{18}$ Jayez and Tovena show that quelque occurs in epistemic contexts and marks inferential evidentiality. Although they share an intriguing connection with (indirect) evidentiality, the Romanian and the French determiner differ in at least three respects: (i) quelque does not need an overt licensor (if the context is clearly hypothetical, quelque can occur in episodic sentences); (ii) quelque does not have an NPI use; (iii) quelque can also be used with abstract, uncountable nouns, unlike vreun.
} 
systematic comparison between vreun and other indefinites is beyond the scope of this paper, but these brief comparative remarks should nevertheless suffice to make the main point: vreun presents an interesting pattern of restricted distribution, which can provide new insights into the parameters of variation among dependent indefinites. The approach to polarity developed in the remainder of this paper has ways to capture the cross-linguistic similarities and differences among dependent indefinites (as discussed at length in Chierchia 2013a), but my main focus at this stage of research concerns the properties of vreun. Accordingly, other indefinites will be considered only when this contributes to a better understanding of the Romanian pattern.

The facts considered in this section complete the picture in Farkas (2002, 2006), by drawing attention to the epistemic versus non-epistemic distinction that governs the behavior of vreun in modal and attitude contexts. The epistemic constraint constitutes an arguably novel way to carve out the data on the distribution of vreun in non-negative polarity contexts. However, both the characterization of vreun and the analysis proposed in the following sections preserve the core intuitions in Farkas' work. More specifically, although implemented in different frameworks, both accounts take the determiner vreun to be an existential element with two different uses and rest on the assumption that alternatives provide the key to understanding its limited distribution. The challenge is not only to account for the restriction to negative polarity and non-factive epistemic contexts, but also to explain the connection between these two uses, while capturing the differences and similarities with other dependent indefinites. The remainder of this paper provides an analysis for the NPI and epistemic uses of vreun that meets these objectives.

\section{An alternatives-and-exhaustification approach to polarity}

In order to provide an account that satisfies the criteria listed above, I adopt the theory developed in Chierchia (2006, 2013a,b), which derives the properties of various types of polarity sensitive items by positing an obligatory association with alternatives. This section introduces the framework and demonstrates how it captures the restricted distribution of polarity items, as well as the fact that certain negative polarity elements can also occur in 'positive', i.e. non-downward-entailing contexts. I present the theory in order to make the paper self-sufficient, but readers familiar with it can safely skip this section and go directly to section 4, which deals with the distribution of vreun.

\subsection{Main assumptions}

Building on insights in Kadmon and Landman (1993), Krifka (1995), Lahiri (1998) and Kratzer and Shimoyama (2002), Chierchia (2006, 2013a,b) develops an alternative-based account of polarity, embedded within a more general theory of meaning enrichment. On this approach, polarity sensitivity is one of the many phenomena whose semantics involves the consideration of alternative semantic values. The theory is couched in a bidimensional semantics (cf. Rooth 1985, 1992), where alternatives are introduced and computed separately from the regular semantic values. The starting point is the interpretation of sentences such as the following: 

a. A: Who came to the party?
B: Paul and Sue.
b. I went to the party, greeted everybody, hugged Paul and Sue and left.
c. A: Mary likes the kids.
B: Not really. She likes PAUL and SUE.

All these utterances convey that Paul and Sue are the only individuals in the context for which a certain property holds, a meaning that goes beyond what is literally said. For example, we understand (40b) as communicating that the speaker hugged Paul and Sue and didn't hug anyone else among the people present at the party. There are two components leading to this enriched, non-literal interpretation: (i) a set of alternatives (e.g. other contextually relevant individuals) and (ii) the exclusion of the (non-entailed) alternatives. This strengthened meaning, i.e. the one obtained via the consideration and exclusion of alternatives, is often triggered by focus, although sometimes context is sufficient to prompt this effect, as in (40b). One of the crucial assumptions in this connection concerns the way meaning enrichment is achieved. In line with van Rooij and Schulz (2006), Fox (2007), Chierchia, Fox and Spector (2012) among others, Chierchia (2013a) argues that enrichment results from applying an exhaustivity operator, such as the one in (41), which is essentially a covert counterpart of only:

$$
\mathrm{O}_{\mathrm{ALT}}(\mathrm{p})=\mathrm{p} \wedge \forall \mathrm{q} \in \mathrm{ALT}[\mathrm{q} \rightarrow \mathrm{p} \subseteq \mathrm{q}] \text {, where } \mathrm{p} \subseteq \mathrm{q} \text { means } \mathrm{p} \text { entails } \mathrm{q}
$$

According to the definition in (41), the exhaustivity operator responsible for strengthening applies to a proposition $p$ and the set of $p$ 's (propositional) alternatives (ALT), and conveys that $p$ (and its entailments) is the only true member of the set of alternatives. ${ }^{19}$ This meaning enrichment mechanism is used not only in the contexts in (40), i.e. question-answer pairs or focus, but is also argued to be responsible for scalar implicatures. For example, the implicature arising in (42a), according to which not all students in the context like syntax, or in (42b), where the disjunction is construed as being exclusive (Maria has a degree in physics or chemistry, but not both):

a. Some students like syntax.

b. Maria has a degree in physics or chemistry.

Scalar terms, such as some and or, lexically activate a set of alternatives, which are factored into meaning via the exhaustivity operator defined above. Applying $\mathrm{O}$ to (42a), with respect to the set of alternatives in (43a), we get the interpretation in (43b), which includes the assertion and the negation of the stronger alternative with all:

a. $\mathrm{ALT}=\{$ some students like syntax, all students like syntax $\}$

\footnotetext{
${ }^{19}$ See Fox (2007) and Chapter 2 in Chierchia (2013a) for detailed discussion of the correct definition of the set of alternatives considered for exhaustification.
} 


\section{b. $\mathrm{O}_{\mathrm{ALT}}($ Some students like syntax $)=$ some students like syntax $\wedge$ $\neg$ all students like syntax}

This briefly illustrates how exhaustification (via O) leads to strengthened interpretations. The details and the motivation for an exhaustification-based theory of scalar implicatures need not concern us here (see Chierchia's work and references therein). For present purposes, the important point is the availability of a covert operator that is used whenever (lexical, focus or contextual) alternatives are factored into meaning. Crucially, for scalar terms, this process is optional; it only takes place if alternatives are relevant for conversational goals.

Polarity items also activate alternatives, an assumption that goes back to Fauconnier (1975). As we will see in section 3.2 below, a phrase such as any student activates domain alternatives, i.e. subsets of (contextually relevant) students. For example, if we are talking about students in humanities, the alternatives could involve students in linguistics and students in history. On the theory adopted here, this is a lexical property of polarity items, which manifests itself regardless of whether alternatives are relevant or not in a given context. What makes a polarity item dependent, as opposed to, say, a simple indefinite, is the fact that the alternatives it brings in must be used (just like alternatives activated through focus). In other words, whereas disjunction or simple indefinites can lead to meaning enrichment, as illustrated in (42)-(43), this process becomes obligatory in the presence of a polarity sensitive indefinite. More concretely, the main hypothesis is that polarity items are indefinites (i.e. existentially quantified elements) that systematically activate sets of alternatives. Active alternatives need to be factored into meaning, i.e. they require the presence of an appropriate alternative-sensitive operator in the structure. ${ }^{20}$ If the insertion of an exhaustivity operator results in a syntactically well-formed structure and leads to a semantically coherent meaning, the polarity item is licensed. If this is not the case, the result is ungrammatical. This is a property shared by all types of polarity items. Variation in the polarity system is captured through a restricted number of parametrical choices, along two interconnected dimensions: (i) nature of alternatives and (ii) modes of exhaustification. Depending on the types of alternatives polarity items activate (e.g. domain, degree or scalar), and the selected exhaustivity operator, ${ }^{21}$ we can derive the properties of various subclasses of polarity items (e.g. weak, strong, emphatic NPIs, 'universal' and existential FCIs, epistemic indefinites).

An important consequence of the fact that exhaustification is conceived as a grammatical mechanism is that it can apply recursively, i.e. to structures that have

\footnotetext{
${ }^{20}$ This requirement is implemented by using a syntactic feature-checking mechanism, which ensures that the exhaustivity operator enters into a syntactic relation akin to agreement with the polarity item. The syntactic details of the theory (concerning features and checking relations with the appropriate exhaustification operator) are entirely set aside in this paper.

21 In addition to the operator in (41), exhaustification can also take place via a covert even, defined as follows (Chierchia 2013a, p.148):

(i) $\mathrm{E}_{\mathrm{ALT}}(p)=p \wedge \forall q \in A L T[p<\mu q]$

( $p<\mu q$ means $p$ is less likely than $q$ with respect to some contextually relevant probability measure $\mu$ ) Even-exhaustification is selected by minimizers, such as give a damn or lift a finger.
} 
already been exhaustified. This idea, which will be relevant for our analysis of vreun, has been used in Fox (2007) to derive free choice effects associated with disjunction in modal contexts. To illustrate Fox's proposal, consider the utterance in (44a), which gives rise to the free choice inference in $(44 \mathrm{~b})$, whereby both the cake and the ice cream are permissible options:

(44) a. You are allowed to eat the cake or the ice cream.

b. You are allowed to eat the cake and you are allowed to eat the ice cream.

The set of alternatives to the disjunctive statement in (44a) includes the corresponding conjunction (the stronger scalar alternative), as well as each of the disjuncts (see Sauerland 2004, Alonso-Ovalle 2005, among others), as represented in (45):

$\mathrm{ALT}=\{\diamond($ eat the cake $\vee$ eat the ice cream $), \diamond($ eat the cake $\wedge$ eat the ice cream), $\diamond$ eat the cake, $\diamond$ eat the ice cream $\}$

Exhaustification over this set amounts to exclusion of non-entailed alternatives (as defined in (41)), which in this case means we exclude all alternatives in ALT. This not only does not derive the desired free choice inference, but actually leads to a contradiction, as it says that it is possible to eat the cake or the ice cream and at the same time, it is not possible to eat either of them:

$\mathrm{O}_{\mathrm{ALT}}(\diamond($ eat the cake $\vee$ eat the ice cream $))=\diamond($ eat the cake $\vee$ eat the ice cream) $\wedge \neg \diamond$ eat the cake $\wedge \neg \diamond$ eat the ice cream $\wedge \neg \diamond$ (eat the cake $\wedge$ eat the ice cream) $=\perp$

Fox's solution consists in assuming that the set of alternatives against which the original assertion is considered includes the exhaustified versions of each of the disjuncts, given in (47):
a. $\mathrm{O}(\triangleright$ eat the cake $)=\oslash$ eat the cake $\wedge \neg \oslash$ eat the ice cream
b. $\mathrm{O}(\oslash$ eat the ice cream $)=\diamond$ eat the ice cream $\wedge \neg \diamond$ eat the cake

The exhaustified version of 'you are allowed to eat the cake' ( $\downarrow$ eat the cake), with respect to the assertion in (44a) can be construed as the answer to the question 'Which of the two options - cake or ice cream - are you allowed to have?'. A possible answer is 'you are allowed to eat the cake', which is typically understood exhaustively - 'you are only allowed to eat the cake', i.e. 'you are allowed to eat the cake and you are not allowed to eat the ice cream'. This interpretation is represented by assuming $\mathrm{O}$ applies to the disjunct ' $\backslash$ eat the cake', as in (47a). Once we exhaustify the assertion with respect to the alternatives in (47), we get the computation in (48), which derives the free choice inference in $(44 b)$ :

$$
\mathrm{O}(\diamond(\text { eat the cake } \vee \text { eat the ice cream }))=
$$


$\diamond$ (eat the cake $\vee$ eat the ice cream)

$\wedge \neg \diamond$ (eat the cake $\wedge$ eat the ice cream)

$\wedge \neg \mathrm{O}(\triangleright$ eat the cake $)$

$\wedge \neg \mathrm{O}(\diamond$ eat the ice cream $)$
ASSERTION

SCALAR ALTERNATIVE

EXHAUSTIFIED DISJUNCTS

$=\diamond$ (eat the cake $\vee$ eat the ice cream $) \wedge \neg \diamond$ (eat the cake $\wedge$ eat the ice cream)

$\wedge \neg(\triangleright$ eat the cake $\wedge \neg \oslash$ eat the ice cream $)$

$\wedge \neg(\diamond$ eat the ice cream $\wedge \neg \oslash$ eat the cake $)$

$=\diamond$ (eat the cake $\vee$ eat the ice cream) $\wedge \neg \diamond$ (eat the cake $\wedge$ eat the ice cream) $\wedge$

$(\diamond$ eat the cake $\rightarrow \diamond$ eat the ice cream $) \wedge(\diamond$ eat the ice cream $\rightarrow \diamond$ eat the cake $)$

$=\diamond$ eat the cake $\wedge \diamond$ eat the ice cream $\wedge \neg \diamond$ (eat the cake $\wedge$ eat the ice cream)

Both the scalar and the pre-exhaustified alternatives are stronger than the assertion, so they must be eliminated. Exhaustification is consistent, i.e. does not give rise to a contradiction (unlike what we saw in (46)). The derived meaning is that it is possible to eat the cake or the ice cream and it is not possible to eat both. Moreover, if one of them is possible, the other one is possible as well. This delivers the desired free choice inference - you are not allowed to have both the cake and the ice cream, but each one of them is an allowable option. ${ }^{22}$

Chierchia (2013a) builds on this proposal to develop a unified theory of free choice effects. Exploiting the parallelisms between disjunction and polarity sensitive indefinites like any or irgendein, the free choice interpretation in modal contexts is argued to come about through the process of 'recursive' exhaustification illustrated above (see also Chierchia 2013b). Polarity sensitive items vary as to whether they tolerate pre-exhaustified alternatives. This is a matter of lexical choice, which determines their behavior. Polarity items that allow pre-exhaustified alternatives can occur in modal contexts (e.g. any or irgendein), for these are the contexts where their consideration leads to consistency and free choice effects. Polarity items that disallow pre-exhaustified alternatives (e.g. ever or lift a finger) do not give rise to free choice inferences and are excluded from modal contexts.

In the following, I will briefly illustrate how the theory captures the distribution of polarity sensitive indefinites that occur in both negative polarity and modal contexts, using examples with the German item irgendein. The presentation stays close to the analysis in Chierchia (2013a), Chapter 5, but the discussion of the

\footnotetext{
${ }^{22}$ The scalar implicature can be removed, e.g. You are allowed to eat the cake or the ice cream, in fact, you are allowed to eat both. There are various ways to derive this. One possibility is to assume that the scalar alternative (SA) is not relevant, and therefore exhaustification is only achieved with respect to dalternatives (i.e. the disjuncts), as discussed in Chierchia (2013a, pp. 141-143). Another possibility is to assume that the scalar inference is computed prior to the modal and separately from d-alternatives (DA):

(i) $\mathrm{O}_{\mathrm{DA}}\left(\diamond \mathrm{O}_{\mathrm{SA}}(\right.$ cake $\vee$ ice cream) $)$

Once (recursive) exhaustification over d-alternatives takes place, we obtain a formula that is compatible with eating both the cake and the ice cream:

(ii) $\diamond(($ cake $\vee$ ice cream $) \wedge \neg($ cake $\wedge$ ice cream $)) \wedge \diamond$ the cake $\wedge \diamond$ ice cream.

Finally, yet another possibility, which would not require separating off exhaustification of scalar and dalternatives, is to follow Fox (2007). His method of avoiding exceedingly strong scalar implicatures relies on the assumption that we start out with pre-exhaustified alternatives.
} 
formal details will be restricted to the elements that are necessary for an explanatory account of vreun, and as such, will remain incomplete. The reader is referred to Chierchia's work for a more detailed presentation of the framework, justification of its core assumptions and comparison with other approaches to polarity.

\subsection{Polarity sensitive indefinites in negative polarity and modal contexts}

Like many other polarity sensitive indefinites, including vreun, the German indefinite determiner irgendein can occur in both negative polarity and modal contexts (see Kratzer and Shimoyama 2002, Kratzer 2005):

a. Niemand hat irgendein Buch mitgebracht. no one had IRGENDEIN book brought along 'No one has brought along any book.'

b. Du darfst mit irgendeinem Professor sprechen. you can with IRGENDEIN professor speak 'You can speak with any professor.'

When occurring in the scope of a modal, irgendein triggers a free choice inference: the sentence in (49b) conveys that the addressee can speak to a professor and any professor (in the relevant domain) is a permissible option. No such free choice inference is present in negative polarity contexts such as (49a), ${ }^{23}$ where irgendein acquires an NPI reading, similar to English any. Both interpretations are derived by assuming irgendein is an existential element that obligatorily activates alternatives. The lexical entry of irgendein is given in (50a) and the sets of alternatives in (50b-c):

$$
\begin{aligned}
& \text { a. \irgendein } \rrbracket=\lambda \mathrm{P} \lambda \mathrm{Q} \exists x \in \mathrm{D}[\operatorname{one}(x) \wedge \mathrm{P}(x) \wedge \mathrm{Q}(x)] \\
& \text { b. Scalar Alternatives } \\
& \qquad \mathrm{SA}=\{\lambda \mathrm{P} \lambda \mathrm{Q} \exists x \in \mathrm{D}[n(x) \wedge \mathrm{P}(x) \wedge \mathrm{Q}(x)] \mid n \in \mathrm{N}\} \\
& \text { c. Domain Alternatives } \\
& \qquad \mathrm{DA}=\left\{\lambda \mathrm{P} \lambda \mathrm{Q} \exists x \in \mathrm{D}^{\prime}[\operatorname{one}(x) \wedge \mathrm{P}(x) \wedge \mathrm{Q}(x)] \mid \mathrm{D}^{\prime} \subseteq \mathrm{D}\right\}
\end{aligned}
$$

According to (50), irgendein is an existential that activates two types of alternatives: (i) scalar and (ii) domain alternatives. The scalar alternatives activated by irgendein are numerical, two, three etc., on a par with the alternatives that can be activated by the simple indefinite $a$ or the numeral one. The domain alternatives consist of all the subsets of $\mathrm{D}$, where $\mathrm{D}$ is the contextually relevant domain of quantification.

With these assumptions in place, let us begin by deriving the interpretation of irgendein in modal contexts such as (49b). The assertion can be represented as in (51a), and the sets of domain and scalar alternatives as in (51b-c):

\footnotetext{
${ }^{23}$ Unless irgendein carries contrastive stress or combines with the particle einfach (nur) 'just'. See Kratzer (2005) for details.
} 
a. Assertion: $\diamond \exists x \in \mathrm{D}[\mathrm{one}(x) \wedge \operatorname{professor}(x) \wedge \operatorname{speak}-\operatorname{to}(\text { you, } x)]^{24}$

b. Domain alternatives:

$$
\left.\mathrm{DA}=\left\{\diamond \exists x \in \mathrm{D}^{\prime}[\text { one }(x) \wedge \operatorname{professor}(x) \wedge \text { speak-to(you, } x)\right]: \mathrm{D}^{\prime} \subseteq \mathrm{D}\right\}
$$

c. Scalar alternatives:

$$
\mathrm{SA}=\{\diamond \exists x \in \mathrm{D}[n(x) \wedge \text { professor }(x) \wedge \operatorname{speak} \text {-to }(\text { you, } x)]: \text { one }<n\}
$$

These alternatives need to be exhaustified, a requirement implemented by assuming they trigger the insertion of an alternative-sensitive operator in the structure, such as the operator $\mathrm{O}$ in (41) above. Keeping the two types of alternatives separate, we use $\mathrm{O}_{\mathrm{DA}}$ and $\mathrm{O}_{\mathrm{SA}}$ to indicate exhaustification over domain and scalar alternatives respectively (52a). ${ }^{25}$ Assuming for simplicity a domain with three professors, (51) can be equivalently represented as in (52), where ' $a$ ' abbreviates '[professor(a) $\wedge$ speakto(you,a)]', 'b' abbreviates '[professor(b) $\wedge$ speak-to(you,b)]' and 'c' abbreviates '[professor (c) $\wedge$ speak-to(you,c)]'. The set of alternatives includes the assertion, scalar alternatives and domain alternatives, as schematized in (52b):

$$
\begin{aligned}
& \text { a. } \mathrm{O}_{\mathrm{DA}} \mathrm{O}_{\mathrm{SA}} \triangleright(\mathrm{a} \vee \mathrm{b} \vee \mathrm{c}) \\
& \text { b. } \quad \nabla(a \vee b \vee c) \\
& \diamond(a \wedge b) \\
& \diamond(b \wedge c) \\
& \diamond(a \vee b) \\
& \diamond(b \vee c) \\
& \diamond a \\
& \Delta b \\
& \diamond(\mathrm{a} \wedge \mathrm{c}) \quad \mathrm{SA}^{26} \\
& \diamond(\mathrm{a} \vee \mathrm{c}) \quad \mathrm{DA}
\end{aligned}
$$

\section{ASSERTION}

Exhaustification over this set of alternatives results in a contradictory statement, as already shown in discussing the behavior of disjunction in modal contexts (cf. (44)). The meaning we get in (53) is that it is possible to talk to one of the three professors in $\mathrm{D}$, but at the same time it is not possible to talk to any one (or any two) of them:

$$
\begin{aligned}
\mathrm{O}_{\mathrm{DA}} \mathrm{O}_{\mathrm{SA}} \nabla(\mathrm{a} \vee \mathrm{b} \vee \mathrm{c}) & =\diamond(\mathrm{a} \vee \mathrm{b} \vee \mathrm{c}) \wedge \neg \nabla(\mathrm{a} \wedge \mathrm{b}) \wedge \neg \nabla(\mathrm{a} \wedge \mathrm{c}) \wedge \neg \nabla(\mathrm{b} \wedge \mathrm{c}) \wedge \\
& \neg \nabla(\mathrm{a} \vee \mathrm{b}) \wedge \neg \nabla(\mathrm{b} \vee \mathrm{c}) \wedge \neg \nabla(\mathrm{a} \vee \mathrm{c}) \\
& \neg \diamond \mathrm{a} \wedge \neg \diamond \mathrm{b} \wedge \neg \nabla \mathrm{c}=\perp
\end{aligned}
$$

Drawing on the similarity with disjunction, we know that this clash can be avoided if we use pre-exhaustified domain alternatives, given in (54). Recall that the

\footnotetext{
${ }^{24}$ I restrict the discussion to possibility modals, but the analysis generalizes to necessity modals. Note that epistemic indefinites, which always take scope below the modal, are 'licensed' by both necessity and possibility modals. In contrast to this, polarity sensitive items that scope above modal operators (such as 'universal' FCIs) are not acceptable under necessity modals (for extensive discussion, see Chierchia 2006, 2013a and Dayal 1998, 2013).

${ }^{25}$ See Chierchia (2013a, pp. 176-190, 277-280) on the differences between exhaustification applying sequentially or to the entire set of alternatives at once and the consequences for the distribution of polarity indefinites.

${ }^{26}$ In the following, I omit the scalar alternative that includes all members of $D, \diamond(a \wedge b \wedge c)$. The result is not affected by this simplification.
} 
exhaustified version of $\backslash \mathrm{a}$ with respect to the original assertion is equivalent to 'only a can hold (and not b or c)', and similarly for all the other alternatives:
a. $\quad \mathrm{O} \diamond(\mathrm{a} \vee \mathrm{b})$
$\mathrm{O} \diamond(\mathrm{b} \vee \mathrm{c})$
$\mathrm{O} \diamond(\mathrm{a} \vee \mathrm{c})$
EXH-DA
$\mathrm{O} \diamond \mathrm{a}$
$\mathrm{O} \diamond \mathrm{b}$
$\mathrm{O} \diamond \mathrm{c}$
b. $\quad \nabla(\mathrm{a} \vee \mathrm{b}) \wedge \neg \vee \mathrm{c} \quad \diamond(\mathrm{b} \vee \mathrm{c}) \wedge \neg \vee \mathrm{a}$
$\diamond(\mathrm{a} \vee \mathrm{c}) \wedge \neg \nabla \mathrm{b}$
EXH-DA

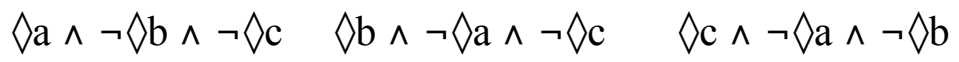

All exhaustified alternatives are stronger than the assertion, so through exhaustification, they will be excluded, as represented in (55a), which is logically equivalent to (55b). This winds up having the enriched meaning in (55c): the assertion and the scalar inference require that only one of the alternatives holds; the computation of exhaustified alternatives amounts to the requirement that if one alternative is possible, so are the others. This can only be satisfied if each one of the three alternatives is possible:

$$
\begin{aligned}
& \text { a. } \mathrm{O}_{\mathrm{DA}} \mathrm{O}_{\mathrm{SA}} \oslash(\mathrm{a} \vee \mathrm{b} \vee \mathrm{c})=\diamond(\mathrm{a} \vee \mathrm{b} \vee \mathrm{c}) \wedge \neg \diamond(\mathrm{a} \wedge \mathrm{b}) \wedge \neg \diamond(\mathrm{a} \wedge \mathrm{c}) \wedge \neg \diamond(\mathrm{b} \wedge \mathrm{c}) \wedge \\
& \text { i. } \neg(\diamond(\mathrm{a} \vee \mathrm{b}) \wedge \neg \diamond \mathrm{c}) \wedge \quad \text { iv. } \neg(\diamond \mathrm{a} \wedge \neg \diamond \mathrm{b} \wedge \neg \diamond \mathrm{c}) \wedge \\
& \text { ii. } \neg(\triangleright(\mathrm{b} \vee \mathrm{c}) \wedge \neg \diamond \mathrm{a}) \wedge \quad \text { v. } \neg(\nabla \mathrm{b} \wedge \neg \diamond \mathrm{a} \wedge \neg \diamond \mathrm{c}) \wedge \\
& \text { iii. } \neg(\diamond(\mathrm{a} \vee \mathrm{c}) \wedge \neg \diamond \mathrm{b}) \wedge \quad \text { vi. } \neg(\diamond \mathrm{c} \wedge \neg \diamond \mathrm{a} \wedge \neg \diamond \mathrm{b}) \\
& \text { b. } \mathrm{O}_{\mathrm{DA}} \mathrm{O}_{\mathrm{SA}} \backslash(\mathrm{a} \vee \mathrm{b} \vee \mathrm{c})=\diamond(\mathrm{a} \vee \mathrm{b} \vee \mathrm{c}) \wedge \neg \nabla(\mathrm{a} \wedge \mathrm{b}) \wedge \neg \diamond(\mathrm{a} \wedge \mathrm{c}) \wedge \neg \diamond(\mathrm{b} \wedge \mathrm{c}) \wedge
\end{aligned}
$$

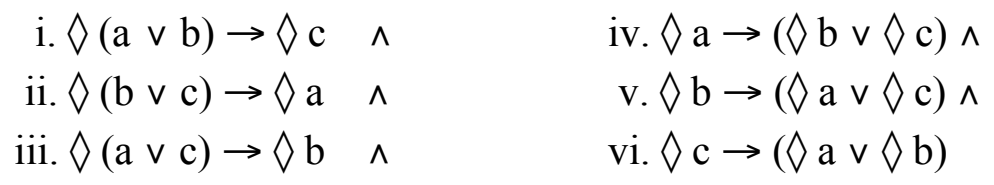

$$
\begin{aligned}
& \text { c. } \mathrm{O}_{\mathrm{DA}} \mathrm{O}_{\mathrm{SA}} \searrow(\mathrm{a} \vee \mathrm{b} \vee \mathrm{c})=\diamond(\mathrm{a} \vee \mathrm{b} \vee \mathrm{c}) \wedge \\
& \text { (Assertion) } \\
& \neg \diamond(\mathrm{a} \wedge \mathrm{b}) \wedge \neg \diamond(\mathrm{a} \wedge \mathrm{c}) \wedge \neg \diamond(\mathrm{b} \wedge \mathrm{c}) \wedge \quad \text { (Scalar inference) } \\
& \diamond \mathrm{a} \wedge \Delta \mathrm{b} \wedge \diamond \mathrm{c}
\end{aligned}
$$

This illustrates how exhaustification yields the enriched meaning of (49b), namely 'you can speak to a professor chosen from the relevant domain of quantification, and each one of them is a possible choice'. ${ }^{27}$ The scalar inference is responsible for the fact that irgendein always has an existential reading; the free choice inference requires variation among the members of the relevant domain of quantification. The derivation of the two inferences is parallel to what happens with disjunction in modal contexts (see (44)). In both cases, the crucial assumption is the existence of active scalar and subdomain alternatives, which can be 'recursively' exhaustified. The main difference between or (or a simple indefinite such as a professor) and irgendein (and more generally polarity sensitive indefinites) is that alternatives associated with the former are only optionally active, whereas those associated with the latter are obligatorily active. This explains why the inferences triggered by irgendein are not optional.

\footnotetext{
27 The strong 'uniqueness' implicature ('you can speak to a single professor') can sometimes be cancelled, just like in the case of free choice readings of disjunction (see fn. 22 for various ways to derive this effect). For simplicity, in the rest of the discussion I set aside this weaker scalar implicature.
} 
Having seen how to derive the inferences observed in modal contexts, let us now turn to negative contexts, such as (49a), where irgendein has a narrow scope existential reading, just like NPIs. To see how this interpretation comes about, assume that the domain relevant for the interpretation of irgendein in (49a) contains three books $\{a, b, c\}$. Using the same representations as before, the assertion to which exhaustification applies looks as in (56a) and the alternatives as in (56b-e):

$$
\begin{array}{llll}
\text { a. } \mathrm{O}_{\mathrm{DA}} \mathrm{O}_{\mathrm{SA}}\left(\neg \exists x \in \mathrm{D} \exists y \in \mathrm{D}^{\prime}[\operatorname{person}(x) \wedge\right. & \text { one }(y) \wedge \operatorname{book}(y) \wedge \operatorname{bring}(x, y)])= \\
\text { b. } \quad \neg(\mathrm{a} \vee \mathrm{b} \vee \mathrm{c}) & & \text { ASSERTION } \\
\mathrm{c.} \neg(\mathrm{a} \wedge \mathrm{b}) & \neg(\mathrm{b} \wedge \mathrm{c}) & \neg(\mathrm{a} \wedge \mathrm{c}) & \text { SA } \\
\text { d. } \neg(\mathrm{a} \vee \mathrm{b}) & \neg(\mathrm{b} \vee \mathrm{c}) & \neg(\mathrm{a} \vee \mathrm{c}) & \text { DA } \\
\quad \neg \mathrm{a} & \neg \mathrm{b} & \neg \mathrm{c} & \\
\text { e. } \neg(\mathrm{a} \vee \mathrm{b}) \wedge \mathrm{c} & \neg(\mathrm{b} \vee \mathrm{c}) \wedge \mathrm{a} & \neg(\mathrm{a} \vee \mathrm{c}) \wedge \mathrm{b} & \text { EXH-DA } \\
\neg \mathrm{a} \wedge(\mathrm{b} \vee \mathrm{c}) & \neg \mathrm{b} \wedge(\mathrm{a} \vee \mathrm{c}) & \neg \mathrm{c} \wedge(\mathrm{a} \vee \mathrm{b}) &
\end{array}
$$

As before, the exhaustification triggered by the insertion of $\mathrm{O}$ seeks to eliminate all stronger alternatives. However, there are no stronger alternatives in this case. Both the scalar alternatives and the plain domain alternatives in (56c-d) are entailed by the assertion, so they cannot be eliminated. Assertion also entails the negation of the exhaustified domain alternatives in (56e). ${ }^{28}$ The result of exhaustification is therefore identical to the assertion in (56a). In other words, no scalar or free choice inference arises and irgendein is interpreted as an existential, i.e. it acquires an NPI-reading. The same conclusion arguably holds for all downward-entailing contexts, where the assertion is always the strongest alternative. On this theory, the NPI-behavior of items like irgendein is a logical consequence of the entailment relations holding in downward-entailing environments.

The hypothesis that polarity sensitive indefinites are existentials with obligatorily active alternatives predicts that these indefinites should be deviant in episodic contexts. As illustrated above, the presence of a downward-entailing or modal operator (together with the availability of pre-exhaustified alternatives) plays a crucial part in making the exhaustification process consistent. In (57), we use a toy example to show that in the absence of any of these operators, exhaustification leads to a contradiction (57b), as it simultaneously requires that one of the alternatives holds $(a \vee b \vee c)$ and that none of them does:

$$
\begin{aligned}
& \text { a. } \quad a \vee b \vee c \\
& \text { ASSERTION } \\
& a \wedge b \quad b \wedge c \quad a \wedge c \quad \text { SA } \\
& a \vee b \quad b \vee c \quad a \vee c \quad D A \\
& \text { a } \quad b \quad c \\
& \text { b. } \mathrm{O}_{\mathrm{DA}} \mathrm{O}_{\mathrm{SA}}(\mathrm{a} \vee \mathrm{b} \vee \mathrm{c})=(\mathrm{a} \vee \mathrm{b} \vee \mathrm{c}) \wedge \neg(\mathrm{a} \wedge \mathrm{b}) \wedge \neg(\mathrm{a} \wedge \mathrm{c}) \wedge \neg(\mathrm{b} \wedge \mathrm{c}) \wedge \\
& \neg(\mathrm{a} \vee \mathrm{b}) \wedge \neg(\mathrm{b} \vee \mathrm{c}) \wedge \neg(\mathrm{a} \vee \mathrm{c}) \wedge \neg \mathrm{a} \wedge \neg \mathrm{b} \wedge \neg \mathrm{c}=\perp
\end{aligned}
$$


This straightforwardly explains why items like any, ever or vreun are ruled out in episodic contexts (such as (1) above). Their alternatives cannot be properly exhaustified. The problem comes from the fact that there are stronger alternatives (every alternative in DA and SA is stronger than the assertion), but we cannot eliminate them in a contradiction-free manner, a situation that results in deviance. ${ }^{29}$ This derives the ungrammaticality of alternative-activating indefinites in episodic sentences. ${ }^{30}$

For certain elements in the polarity system, such as irgendein, a last resort strategy can rescue their use in sentences such as (58):

Irgendein Student hat angerufen.

IRGENDEIN student has called

'Some student or other called.'

Despite the fact that (58) makes reference to a single event, i.e. it is an episodic statement, irgendein can be used. The sentence triggers a modal inference, which we can paraphrase as 'Some student called; for all the speaker knows, it might be any student (the speaker is ignorant as to the identity of the caller)'. Following Kratzer and Shimoyama (2002), this ignorance reading, which characterizes so-called epistemic indefinites (see the discussion in section 2.1), is assumed to arise through a covert assertoric modal. The LF of (58) is thus as given in (59) below, where $\square_{\mathrm{S}}$ means something like 'the speaker knows that':

$$
\mathrm{O}_{\mathrm{DA}} \mathrm{O}_{\mathrm{SA}} \square_{\mathrm{S}} \text { [irgendein student hat angerufen] }
$$

The presence of the epistemic modal in (59) renders exhaustification consistent and derives the ignorance inference mentioned above. If the modal were bouletic/goaloriented, the indefinite would convey indifference (i.e. the speaker/the relevant agent does not care about the referent of the indefinite). As Chierchia shows, if neither an ignorance nor an indifference reading is possible in a given context, irgendein cannot be used (Chierchia 2013a, p. 257):

(60) John hat geschummelt. *Deshalb ist irgendein Student aus deiner Klasse ein Betrueger.

'John cheated. Therefore some student in your class is a cheater.'

Languages and indefinites vary with respect to whether and when they allow this strategy. Future empirical work needs to determine the restrictions on the distribution

\footnotetext{
${ }^{28}$ Excluding an exhaustified alternative, such as $\neg \mathrm{O} \neg(\mathrm{a} \vee \mathrm{b})=\neg(\neg(\mathrm{a} \vee \mathrm{b}) \wedge \mathrm{c})$ amounts to $\mathrm{c} \rightarrow(\mathrm{a} \vee \mathrm{b})$, and similarly for all other alternatives.

${ }^{29}$ Note that recursive exhaustification, the consideration of pre-exhaustified domain alternatives also yields a contradiction in these sentences (see Chierchia 2013a, p. 255 for details).

${ }^{30}$ For details on when and why contradictions give rise to ungrammaticality, the reader is referred to Gajewski (2002) and Chierchia (2013a, pp. 42-54).
} 
and nature of null modals, and explain their interaction with various kinds of indefinites. We limit ourselves to pointing out the explanation offered by Chierchia (and other alternative-based approaches) for the acceptability of certain dependent indefinites in seemingly episodic sentences such as (58). If we grant the existence of covert modality as a possible rescue mechanism, the theory offers a principled explanation for three distributional properties shared by a wide range of polarity sensitive indefinites: (i) exclusion from episodic contexts, (ii) occurrence in downward-entailing contexts and (iii) the need for a modal operator in nondownward-entailing contexts.

Crucially, there is no 'licensing' involved: the way alternatives are computed in positive (i.e. upward-entailing), modal and downward-entailing contexts is independent of polarity items, as can be easily checked by looking at the behavior of disjunction or numerals (whose implicatures also typically disappear in downwardentailing contexts). As previously mentioned, the key difference between dependent indefinites like irgendein or any and scalar terms like or lies in the fact that the former, but not the latter, obligatorily activate alternatives. This is the property that is ultimately responsible for the narrower distribution of polarity sensitive elements.

\section{An alternative-based account for vreun}

This section proposes an alternative-and-exhaustification account for vreun, adopting the theory introduced in the previous section. We start with the distributional properties that follow without any further assumptions (section 4.1) and then focus on the epistemic constraint documented in section 2 above.

\subsection{Situating vreun in the polarity system}

The alternatives-and-exhaustification theory outlined above straightforwardly derives the properties that vreun shares with irgendein and many other polarity sensitive indefinites, namely the restriction to downward-entailing and modal contexts. The key assumption is the obligatory association with two kinds of alternatives: (i) scalar and (ii) subdomain alternatives, both of which need to be exhaustified (via recursive applications of $\mathrm{O}$ ). The presence of the DE or modal operator makes exhaustification consistent, explaining why vreun requires them. The derivation of the sentences in (61) is thus parallel to that discussed for (49), and as such, will not be repeated here: 

a. Lisa $n u$ a citit vreo carte. $^{31}$
Lisa NEG has read VREUN book
'Lisa didn't read any book.'
b. Se poate ca Maria să se fi întâlnit cu vreun prieten. REFL may that Maria SUBJ REFL be met with VREUN friend 'Maria might have met some friend.'

There is however an important aspect in which vreun differs from irgendein, namely its behavior in episodic contexts. Recall that vreun is systematically ruled out from episodic sentences (as illustrated in (1)). This happens even in environments where the ignorance reading is very salient, making it plausible to assume the presence of a null modal (see (21)). On the basis of this, we must conclude that covert modality cannot rescue vreun. As mentioned above, the availability of this strategy varies across items and across languages. In this respect, vreun might be like any-numeral construction, e.g. any two books, which is also ruled out in episodic contexts (see e.g. Dayal 2013 and Chierchia 2013a). While the absence of the 'null modal' option for vreun needs to be understood, the crucial point is that once this rescue strategy is construed as optional, the behavior of vreun in episodic statements is expected on the alternative-based approach sketched in section 3. Since exhaustification leads to deviance in the absence of a downward-entailing or modal operator (see (57) above), vreun is predicted to be ruled out in episodic environments.

However, recall from section 2 that vreun is subject to a further distributional restriction, namely the epistemic constraint in (17). Nothing in the analysis given so far accounts for the different behavior in the scope of epistemic and non-epistemic operators. In the remainder of this paper, I propose a way to extend the alternativebased analysis and derive the epistemic constraint. To this end, we need to import one more piece of the formal apparatus of Chierchia's theory, namely the difference between what are known as partial and total variation indefinites (section 4.2). This will lead to a better understanding of the interpretation of vreun in modal contexts and the differences with other indefinites. In section 4.3, I argue that the epistemic constraint follows from a further condition on the set of alternatives activated by vreun, a condition that taps into the distinction between partial and total variation.

\footnotetext{
${ }^{31}$ I take the restrictions on the use of vreun in negative sentences discussed in section 1.2 and 2.5 to be the result of a blocking effect induced by negative concord items. I am not aware of any explanatory theory of blocking, which could predict when it is active and when it isn't, but it is clear that we are dealing with a widespread phenomenon (cf. Hoeksema 1999, Horn 2001, Perelstvaig 2004, among others). In the framework adopted here, the blocking effect of negative concord can be viewed as an instance of competition between strong NPIs (negative concord items) and weak NPIs (e.g. vreun), with a preference for the strong version under negation. The viability of this route depends on how exactly it gets implemented (see Chapter 4 in Chierchia 2013a for an alternative-based treatment of negative concord). But the frequency of such blocking effects lends support to a unitary approach to NPIs and negative concord items, which views them as parts of the same system, with the same possible sources of variation (restrictions on alternatives and exhaustification).
} 


\section{2 'Total' versus 'partial' variation}

The first aspect of the interaction between vreun and modal operators that needs to be understood is the modal inference it gives rise to. More precisely, we know that vreun signals speaker's ignorance with respect to the identity of the individual denoted by the indefinite. This makes it incompatible with continuations that specify the referent of the vreun-phrase, a property shared by a large number of epistemic indefinites, including German irgendein (e.g. Kratzer and Shimoyama 2002, Aloni and Port 2010), Italian un qualche and un NP qualunque (e.g. Chierchia 2006), French quelque and un NP quelconque (e.g. Jayez and Tovena 2007), Spanish algún (e.g. AlonsoOvalle and Menéndez-Benito 2008, 2010) or Romanian un NP oarecare (e.g. Săvescu-Ciucivara 2007). One crucial dimension along which epistemic indefinites vary concerns the extent of variation ('freedom of choice') imposed on the domain of quantification, which can be total or partial. ${ }^{32}$ On the one hand, it has been argued that certain epistemic indefinites (e.g. irgendein, un NP qualunque, un NP oarecare) can sustain TOTAL variation, requiring that all relevant alternatives in the domain of quantification qualify as equally possible options (as in (49b) above). For example, the sentence in (62), with the Romanian epistemic indefinite un NP oarecare, states that Maria has the obligation to work with a colleague and it could be any colleague:

$$
\begin{aligned}
& \text { Maria trebuie să lucreze cu un coleg oarecare. } \\
& \text { Maria must SUBJ work with a colleague OARECARE } \\
& \text { 'Maria must work with a colleague, any colleague.' }
\end{aligned}
$$

In contrast to this total freedom of choice, we find epistemic indefinites that trigger a weaker inference - PARTIAL variation - some, but not necessarily all alternatives in the relevant domain are epistemic possibilities. As such, they are compatible with the exclusion of some of the possible options. The difference can be most readily observed in the scenario in (63), due to Alonso-Ovalle and Menéndez-Benito (2010):

(63) Maria, Juan, and Pedro are playing hide-and-seek in their country house. Juan is hiding. Pedro believes that Juan is inside the house, but not in the bathroom or in the kitchen.

a. Juan tiene que estar en alguna habitación de la casa.

b. Juan trebuie să fie în vreo cameră din casă.

'Juan must be in a room of the house.'

The context makes it clear that not all rooms of the house are possible choices, i.e. the variation associated with the indefinite is limited to a subset of elements in the

\footnotetext{
32 There is some variation in the literature concerning the terminology used, although insofar as I can tell, all the studies mentioned above refer to the same phenomenon. In this paper, 'Partial Variation' corresponds to 'Modal Variation', while 'Total Variation' to 'Free Choice' (or 'Domain Widening'), in work by Alonso-Ovalle and Menéndez-Benito, and Aloni and Port. For a related proposal, see Jayez and Tovena (2007).
} 
relevant domain. While the use of algún or vreun is perfectly acceptable in this scenario, a total variation item like un NP oarecare or qualunque would be deviant.

In order to derive the different modal inferences, the alternative-based framework adopted here capitalizes on the proposal in Alonso-Ovalle and MenéndezBenito $(2008,2010)$, which attributes the total/partial variation distinction to different sets of domain alternatives. Let me first briefly summarize their account. In line with the approach in Kratzer and Shimoyama (2002) on which they build, Alonso-Ovalle and Menéndez-Benito derive the inferences triggered by epistemic indefinites as conversational implicatures arising via Gricean reasoning. The difference between total and partial variation is shown to stem from different constraints on the domain of quantification associated with the epistemic indefinite: whereas total variation indefinites like irgendein act as domain wideners, partial variation indefinites like algún impose an anti-singleton constraint on their domain (i.e. they signal that their domain is not a singleton). The quantificational domain determines the alternative assertions that would have resulted from the consideration of a different domain. They are obtained by considering either all subsets of the maximal domain of quantification (irgendein) or singleton sets only (algún). Standard Gricean reasoning over these alternatives leads to the modal inferences described above.

Let us see how Chierchia generalizes this insight and integrates it in the alternatives-and-exhaustification framework. ${ }^{33,34}$ On his approach, epistemic indefinites, like all other elements in the polarity system, have active alternatives (as part of their lexical semantics). The total/partial variation distinction stems from different lexically activated subdomain alternatives: if the domain alternatives are 'large', i.e. they include any possible subset of $\mathrm{D}$, the resulting meaning is a total variation, free choice interpretation - there is a single individual satisfying the existential claim and all relevant alternatives qualify as possible options; if the domain alternatives to which exhaustification applies are 'small' (singletons), the resulting meaning is partial variation - some, but not necessarily all, alternatives qualify as options. The choice between these two kinds of alternatives is a lexical property of the epistemic indefinite. The observed modal inferences arise from regular (recursive) exhaustification over the sets of active alternatives.

The derivation of the meaning of irgendein in modal contexts (section 3.2) has already illustrated how the computation of 'large' domain alternatives leads to free choice effects in Chierchia's theory. In order to show how the posited difference in domain alternatives affects the extent of variation associated with the epistemic indefinite, I will use examples with Romanian indefinites and contrast the

\footnotetext{
${ }^{33}$ See Fălăuş (2009) for a first attempt to integrate Alonso-Ovalle and Menéndez-Benito's hypothesis in the alternatives-and-exhaustification framework, in order to capture the difference between vreun and un oarecare.

${ }^{34}$ A detailed comparison with Alonso-Ovalle and Menéndez-Benito's work lies beyond the scope of this paper. Let me just point out that the two accounts are couched in different alternative-based frameworks, and refer the reader to Chierchia (2013a,b) and Fălăuş (2013) for remarks on the similarities and differences between the present approach and the Hamblin style semantics in Kratzer and Shimoyama (2002).
} 
interpretation of vreun (a partial variation indefinite) and un NP oarecare (total variation) in the scope of a possibility modal:

a. Maria poate să se căsătorească cu un doctor oarecare.

Maria may SUBJ REFL marry with a doctor OARECARE

'Maria may marry a doctor, any doctor.'

b. Se poate ca Maria să se căsătorească cu vreun doctor.

REFL may that Maria SUBJ REFL marry with VREUN doctor

'Maria might marry some doctor or other.'

Setting aside for now the fact that the possibility modal has a deontic construal in (64a) and an epistemic one in (64b), ${ }^{35}$ let us consider the two sentences under the following LF representation:
a. $\diamond\left[\right.$ a doctor $_{i}\left[\right.$ Maria marries $\left.\left.\mathrm{t}_{\mathrm{i}}\right]\right]$
b. Assertion: $\diamond \exists x \in \mathrm{D}[\operatorname{one}(x) \wedge \operatorname{doctor}(x) \wedge \operatorname{marry}(\operatorname{Maria}, x)]$

The assertion is identical to what we would have with a simple indefinite. However, unlike ordinary indefinites, both un oarecare and vreun activate two kinds of alternatives, scalar and domain, requiring exhaustification. As far as scalar alternatives are concerned, the two indefinites behave identically - they activate the alternatives in (66a):

a. $\mathrm{SA}=\{\triangleright \exists x \in \mathrm{D}[n(x) \wedge \operatorname{doctor}(x) \wedge \operatorname{marry}($ Maria, $x)] \mid n \in \mathbf{N}\}$

b. Exhaustification over scalar alternatives

$$
\mathrm{O}_{\mathrm{SA}} \diamond(\mathrm{a} \vee \mathrm{b} \vee \mathrm{c})=\diamond(\mathrm{a} \vee \mathrm{b} \vee \mathrm{c}) \wedge \neg \diamond(\mathrm{a} \wedge \mathrm{b}) \wedge \neg \diamond(\mathrm{a} \wedge \mathrm{c}) \wedge \neg \diamond(\mathrm{b} \wedge \mathrm{c})
$$

Assuming a domain with only three individuals, we exhaustify over scalar alternatives and add the scalar implicature to the assertion, thus obtaining (66b), interpreted as 'Maria may marry a doctor in $\{a, b, c\}$, and it is not possible that she marries two doctors'. This meaning component is shared by un NP oarecare and vreun, and more generally, by total and partial variation indefinites, and is ultimately responsible for their existential interpretation. Nothing new thus far.

More interesting is the computation of domain alternatives, which constitutes the source of the total vs. partial variation distinction. More precisely, Chierchia assumes that (i) the activation of all subdomain alternatives leads to total variation (sustained by un NP oarecare) and (ii) the activation of singleton domain alternatives is responsible for partial variation (which we see in the case of vreun). The domain alternatives for un oarecare are schematized in (67):

\footnotetext{
${ }^{35}$ To provide a real minimal pair, we would have to use un oarecare in an epistemic context. However, most speakers find un oarecare degraded or entirely deviant with epistemic modal auxiliaries. For details on the distribution and interpretation of un oarecare in modal contexts, see Fălăuş (to appear).
} 


$$
\begin{aligned}
& \text { a. } \quad \nabla(a \vee b \vee c) \\
& \nabla(\mathrm{a} \vee \mathrm{b}) \quad \nabla(\mathrm{b} \vee \mathrm{c}) \quad \nabla(\mathrm{a} \vee \mathrm{c}) \quad \text { DA } \\
& \diamond \mathrm{a} \quad \Delta \mathrm{b} \quad \Delta \mathrm{c} \\
& \text { b. } \diamond(\mathrm{a} \vee \mathrm{b}) \wedge \neg \nabla \mathrm{c} \quad \forall(\mathrm{b} \vee \mathrm{c}) \wedge \neg \nabla \mathrm{a} \quad \forall(\mathrm{a} \vee c) \wedge \neg \diamond \mathrm{b} \quad \text { EXH-DA } \\
& \diamond \mathrm{a} \wedge \neg \diamond \mathrm{b} \wedge \neg \mathrm{c} \quad \diamond \mathrm{b} \wedge \neg \nabla \mathrm{a} \wedge \neg \nabla \mathrm{c} \quad \nabla \mathrm{c} \wedge \neg \nabla \mathrm{a} \wedge \neg \nabla \mathrm{b}
\end{aligned}
$$

In (67a), we have the plain domain alternatives activated by un oarecare (familiar from the interpretation of irgendein given in section 3.2). They consist of all the subsets of the quantificational domain, which in the case at hand means subsets of doctors. The sets of alternatives in (67b) are the exhaustified versions of the domain alternatives activated by the indefinite, which are obtained by attaching $\mathrm{O}$ in front of each of the domain alternatives in (67a). For example, ' $\(a \vee b) \wedge \neg \backslash c$ ' stands for 'Maria may only marry doctor a or b', i.e. she may not marry doctor c, and ' $\ \mathrm{a} \wedge \neg \backslash \mathrm{b} \wedge \neg \backslash \mathrm{c}$ ' stands for 'Maria may only marry doctor a', i.e. she may not marry doctor $b$ or doctor c. Similarly for all other alternatives.

In contrast to this, the set of domain alternatives activated by partial variation indefinites such as vreun is smaller - it only includes (pre-exhaustified) singleton domain alternatives. In other words, for vreun, we only consider domain alternatives of the kind 'Maria may only marry doctor a (and not b or c)', as represented in (68):

$$
\begin{aligned}
& \text { a. } \quad \forall(a \vee b \vee c) \quad \text { ASSERTION } \\
& \nabla \mathrm{a} \quad \Delta \mathrm{b} \quad \Delta \mathrm{c} \quad \text { DA } \\
& \text { b. } \diamond \mathrm{a} \wedge \neg \diamond \mathrm{b} \wedge \neg \nabla \mathrm{c} \diamond \mathrm{b} \wedge \neg \nabla \mathrm{a} \wedge \neg \nabla \mathrm{c} \quad \nabla \mathrm{c} \wedge \neg \nabla \mathrm{a} \wedge \neg \diamond \mathrm{b} \quad \text { EXH-DA }
\end{aligned}
$$

Working things out, we compute the enriched meaning of the sentences in (64), by putting together the assertion with the negation of all the exhaustified alternatives, which yields the following meaning:

a. Exhaustification over the alternatives activated by un oarecare

$$
\begin{aligned}
& \mathrm{O}_{\text {EXH-DA }} \oslash(\mathrm{a} \vee \mathrm{b} \vee \mathrm{c})=\diamond(\mathrm{a} \vee \mathrm{b} \vee \mathrm{c}) \wedge \neg \diamond(\mathrm{a} \wedge \mathrm{b}) \wedge \neg \diamond(\mathrm{a} \wedge \mathrm{c}) \wedge \neg \diamond(\mathrm{b} \wedge \mathrm{c}) \wedge \\
& \checkmark \mathrm{a} \wedge \Delta \mathrm{b} \wedge \Delta \mathrm{c} \quad \Rightarrow \text { TOTAL VARIATION }
\end{aligned}
$$

b. Exhaustification over the alternatives activated by vreun

$$
\begin{aligned}
& \left.\mathrm{O}_{\text {ЕХн-DA }} \backslash(\mathrm{a} \vee \mathrm{b} \vee \mathrm{c})=\diamond(\mathrm{a} \vee \mathrm{b} \vee \mathrm{c}) \wedge \neg \diamond(\mathrm{a} \wedge \mathrm{b}) \wedge \neg\right\rangle(\mathrm{a} \wedge \mathrm{c}) \wedge \neg \nabla(\mathrm{b} \wedge \mathrm{c}) \wedge \\
& ((\mathrm{a} \wedge \triangleright \mathrm{b}) \vee((\mathrm{a} \wedge \backslash \mathrm{c}) \vee(\diamond \mathrm{b} \wedge \backslash \mathrm{c}) \quad \Rightarrow \text { PARTIAL VARIATION }
\end{aligned}
$$

We are already familiar with the enriched meaning obtained by exhaustification over domain alternatives of any size, given in (69a), which results in a typical free choice interpretation, requiring that each alternative of $a, b$ and $c$ be a possibility - a total variation effect. This, together with the assertion enriched by the scalar implicature, yields the standard reading of total variation indefinites like un NP oarecare: Maria can marry some doctor in the relevant domain $(\{a, b, c\})$ and any doctor is a possible option. In contrast to this, the meaning induced by singleton domain alternatives requires that if some alternative is true, at least some other must be (69b). To put it 
differently, at least two of the alternatives are true in some world, but not necessarily all of them (partial variation).

This demonstrates how Chierchia is able to exploit a small difference in the choice of alternatives to derive different interpretive effects. Just like polarity elements vary as to whether they allow pre-exhaustified domain alternatives, a lexical property, the activation of all domain alternatives vs. singletons distinguishes total and partial variation indefinites. This captures the different inferences triggered by vreun and the closely related existential un NP oarecare. The restriction to singleton domain alternatives has no impact in downward-entailing contexts, where the assertion always entails the alternatives (regardless of whether they are restricted to minimal subdomains). But it proves crucial in deriving the weaker modal inference triggered by vreun (and other partial variation indefinites) in modal contexts. Once we adopt Chierchia's theory, we have a uniform analysis of vreun in NPI and modal contexts, which also captures some of the differences with other indefinites, e.g. the closely related item un oarecare. However, the account does not yet explain the restriction to epistemic contexts, which sets vreun apart from the epistemic indefinites documented to date. This is the challenge I undertake in the next section.

\subsection{Deriving the epistemic constraint}

In section 2 above, we examined the occurrences of vreun in non-negative polarity contexts and argued that the lexical semantics of the relevant operators necessarily includes an 'uncertainty' component, an intuition that I subsumed under the epistemic constraint in (17). This generalization was shown to bring together epistemic modals (closely related to the presumptive mood), epistemic attitude verbs like think, assume and hope, while at the same time excluding others, in particular deontic modalities and related attitude verbs (e.g. request, suggest, want). The question that we need to address is how to derive such a constraint on the theory of polarity adopted here. Ideally, we should be able to do it by exploiting the two elements responsible for variation elsewhere in the polarity system: alternatives and modes of exhaustification. In other words, vreun should activate scalar and singleton domain alternatives, like it always does; exhaustification over these alternatives will be consistent in epistemic contexts, but will clash with the lexical semantics of deontics and other intensional operators that don't fall under the epistemic constraint. The question then becomes what kind of condition on alternatives or exhaustification can generate this behavior. In the following, I submit the hypothesis that the restriction to epistemic contexts results from a further condition on the domain alternatives associated with vreun.

Let me first give an informal overview of the account (first proposed in Fălăuş 2010). As we will see shortly, in languages that have both total and partial variation epistemic indefinites, the use of a partial variation epistemic indefinite can optionally give rise to an 'anti-total variation' implicature. Capitalizing on this observation, I argue that this implicature is built into the meaning of vreun, i.e. it has been lexicalized. This hypothesis will be implemented by assuming that vreun includes among its active alternatives the total variation indefinite un oarecare (which comes 
with its own alternatives). A second building block of my proposal relates to the independently observable fact that certain modal operators, when taking existentials in their scope, trigger free choice, total variation effects. The lexical meaning of vreun is going to clash with the semantics of these inherently free choice modals. On the proposed account, the more restricted distribution of vreun will therefore once again be derivable from the interaction between its lexical semantics and the semantic properties of the embedding operator.

\subsubsection{The ban on total variation}

Let us start by focusing on the conjectured ban on total variation. We have seen that vreun behaves on a par with algún or un qualche and sustains partial variation, being compatible with situations where not all individuals in the domain of quantification constitute possible values for the existential claim (as in the hide-and-seek scenario in (63) above). Pursuing this line of thinking, I argue that vreun differs from other partial variation indefinites by imposing a stronger constraint, i.e. not only does vreun allow partial variation, but actually requires it. In other words, for vreun to be appropriate, we must rule out the option of total variation, which would allow any member of the domain to be a possible alternative. Let me now show what motivates this proposal.

As we know, partial variation epistemic indefinites like un qualche or algún convey a weaker modal inference than total variation elements. Interestingly, the use of a partial variation indefinite can give rise to an optional 'anti-total variation' implicature, as illustrated by the following example (due to Chierchia 2013a, p. 286):

(70) Voglio sposare un qualche linguista

'I want to marry some linguist or other,

a. ... ma non un linguista qualsiasi. Non sposerei mai un semanticista. but not any old linguist. I would never marry a semanticist.'

b. ... uno qualsiasi.

\section{a QUALSIASI}

'I want to marry some linguist; anyone will do.'

The sentence in (70) can trigger the implicature in (70a), and convey that the speaker would not be happy with any linguist in the relevant quantificational domain, e.g. not a semanticist. But this meaning effect is clearly removable, as (70b) shows.

The difference, I claim, between un qualche (and other partial variation epistemic indefinites) and vreun is that the latter 'grammaticizes' this anti-total variation inference. In other words, vreun is incompatible with total variation scenarios. If, for example, all rooms were known to be possible options in the hideand-seek scenario in (63), vreun would be deviant. The following scenario, which is parallel to the card game in (28), further illustrates the ban on total variation:

(71) The 'shell game' requires three shells or boxes and a small ball. The ball is placed under one of the boxes and the operator quickly shuffles the boxes around. In order to win, the player has to identify the box containing the ball. 
\#Mingea trebuie să fie în vreo cutie.

ball-the must SUBJ be.3SG in VREUN box

'The ball must be in some box or other.'

The context in (71) makes it clear that the ball could be in any of the three boxes under consideration, although the speaker does not know which box is the right one. However, despite the ignorance concerning the box satisfying the modal claim, vreun cannot be used. The reason, I submit, is the incompatibility with total variation, which I take to be a restriction built into the semantics of vreun. Insofar as I can tell, no such restriction is associated with other partial variation items: they are not used to convey total variation, but are perfectly compatible with such set-ups. ${ }^{36}$

Let me first show how such an effect could be obtained compositionally within our general framework and then discuss its consequences for the distribution of vreun. We are trying to build into the meaning of vreun an anti-total variation inference. We know that the total variation inference in Romanian is normally triggered by un oarecare (cf. (64) above). The Italian examples in (70) suggest that partial and total variation indefinites form a scale, where the lower element on the scale can trigger the inference that the stronger alternative does not hold. If vreun and un oarecare are scale-mates, an arguably plausible way to implement this additional condition is to assume that vreun lexicalizes a (strong) form of competition with the total variation indefinite un NP oarecare. ${ }^{37}$ More specifically, I conjecture that the set of formal alternatives activated by vreun includes un oarecare. Since un oarecare is itself an alternative-bearing element, this implies that vreun takes among its alternatives both the total variation indefinite un oarecare and the alternatives activated by un oarecare. The full set of alternatives activated by vreun thus includes not only the usual scalar and singleton domain alternatives (72b-c), but also the 'complex' alternatives brought about by the competition with un oarecare $(72 \mathrm{~d})$ :
a. $\llbracket v$ reun $\rrbracket=\lambda \mathrm{P} \lambda \mathrm{Q} \exists x \in \mathrm{D}[$ one $(x) \wedge \mathrm{P}(x) \wedge \mathrm{Q}(x)]$
b. $\mathrm{SA}=\{\lambda \mathrm{P} \lambda \mathrm{Q} \exists x \in \mathrm{D}[n(x) \wedge \mathrm{P}(x) \wedge \mathrm{Q}(x)] \mid n \in \mathbf{N}\}$
c. $\mathrm{DA}=\{\lambda \mathrm{P} \lambda \mathrm{Q} \exists x \in\{\mathrm{a}\}[\operatorname{one}(x) \wedge \mathrm{P}(x) \wedge \mathrm{Q}(x)] \mid \mathrm{a} \in \mathrm{D}\}$

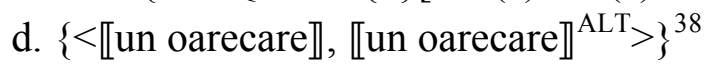

The anti-total variation effect is going to result from exhaustification over singleton domain alternatives (which preserves the usual partial variation effect) and over the

\footnotetext{
${ }^{36}$ For example, my Spanish informants accept the use of algún in this context, both on its partitive and non-partitive version. Partitive vreun is also acceptable (see the discussion in section 2.5).

${ }^{37}$ To make this point more convincingly, one would also need to provide a detailed discussion of the properties of un oarecare, something which cannot be done here. For evidence that vreun and un oarecare have complementary distributions and interpretations, see Fălăuş (to appear).

${ }^{38}$ Once we allow for complex alternatives of this kind, the notion of functional application for alternatives will have to be suitably generalized, as usually assumed for focus alternatives, cf. e.g. Rooth (1985), Krifka (2006):

(i) (Recursive) Pointwise Functional application If $\llbracket(\alpha \beta) \rrbracket=f(\llbracket \alpha \rrbracket, \llbracket \beta \rrbracket)$, then $\llbracket(\alpha \beta) \rrbracket^{\mathrm{ALT}}=\left\{\mathrm{f}(\mathrm{X}, \mathrm{Y}) \mid \mathrm{X} \in \llbracket \alpha \rrbracket^{\mathrm{ALT}}, \mathrm{Y} \in \llbracket \beta \rrbracket^{\mathrm{ALT}}\right\}$
} 
complex alternatives in (72d) (,which leads to the ban on total variation). One question that might arise concerns the order in which these alternatives are considered. In the following, I assume that we first compute complex alternatives $<\phi$, $\phi^{\mathrm{ALT}}>$, which results in the usual total variation inference (along the lines of (67) and (69) above). The result is added to the set of domain alternatives and exhaustification then proceeds in the usual manner. For illustration, consider the following sentence with vreun under a possibility modal:

(73) Poate Maria s-a întâlnit cu vreun prieten. maybe Maria REFL-has met with VREUN friend 'Maybe Maria met some friend.'

Exhaustification with respect to scalar alternatives works as before (see (66)), so let us concentrate on the alternatives responsible for the anti-total variation inference. The novelty with respect to previous examples lies in the consideration of complex alternatives (72d). Simply put, the computation of these alternatives yields the meaning effect we would obtain if un oarecare were used in (73); in a domain with three elements, this winds up in the standard total variation inference, derived as in (69) above, repeated in (74):

$$
\begin{aligned}
\mathrm{O}_{\text {EXH-DA }} \triangleright(\mathrm{a} \vee \mathrm{b} \vee \mathrm{c})= & \diamond(\mathrm{a} \vee \mathrm{b} \vee \mathrm{c}) \wedge \neg \mathrm{O} \diamond(\mathrm{a} \vee \mathrm{b}) \wedge \neg \mathrm{O} \diamond(\mathrm{a} \vee \mathrm{c}) \wedge \neg \mathrm{O} \diamond(\mathrm{b} \vee \mathrm{c}) \wedge \\
& \neg \mathrm{O} \diamond \mathrm{a} \wedge \neg \mathrm{O} \diamond \mathrm{b} \wedge \neg \mathrm{O} \diamond \mathrm{c} \\
= & \diamond \mathrm{a} \wedge \diamond \mathrm{b} \wedge \triangleleft \mathrm{c}
\end{aligned}
$$

In prose, this amounts to the statement that Maria could be with any of the three individuals in the domain. Now, adding this to the set of formal alternatives we are assuming for vreun, the full set of alternatives for the sentence in (73) to which exhaustification is going to apply is the one in (75): it includes the assertion (like it always does), the set of exhaustified singleton domain alternatives (familiar from previous examples, see (68)) and the alternatives corresponding to the complex alternative associated with un oarecare:

$$
\begin{aligned}
& \llbracket(73) \rrbracket^{\mathrm{ALT}}=\{\diamond(\mathrm{a} \vee \mathrm{b} \vee \mathrm{c}), \quad \text { Assertion } \\
& \mathrm{O} \vee \mathrm{a}, \mathrm{O} \diamond \mathrm{b}, \mathrm{O} \diamond \mathrm{c}, \quad \text { Exhaustified singleton domains } \\
& \mathrm{O}_{\text {EXH-DA }} \oslash(\mathrm{a} \vee \mathrm{b} \vee \mathrm{c}) \quad \text { Total Variation un oarecare }(74) \\
& \diamond(\mathrm{a} \wedge \mathrm{b}), \diamond(\mathrm{a} \wedge \mathrm{c}), \diamond(\mathrm{b} \wedge \mathrm{c}) \quad \text { \} Scalar alternatives }
\end{aligned}
$$

Exhaustification with respect to the set of alternatives in (75) yields the following anti-total variation inference:

$$
\begin{aligned}
& \text { a. } \mathrm{O}_{\mathrm{ALT}}(\nabla(\mathrm{a} \vee \mathrm{b} \vee \mathrm{c}))=\diamond(\mathrm{a} \vee \mathrm{b} \vee \mathrm{c}) \wedge \\
& \wedge \neg \diamond(\mathrm{a} \wedge \mathrm{b}) \wedge \neg \nabla(\mathrm{a} \wedge \mathrm{c}) \wedge \neg\rangle(\mathrm{b} \wedge \mathrm{c})
\end{aligned}
$$

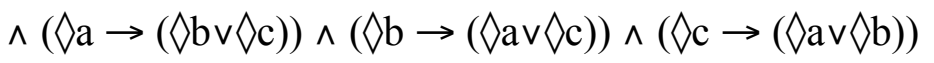




$$
\begin{aligned}
& \wedge \neg(\diamond \mathrm{a} \wedge \diamond \mathrm{b} \wedge \diamond \mathrm{c}) \\
& \text { b. }=(\ \mathrm{a} \wedge \Delta \mathrm{b}) \vee((\mathrm{a} \wedge \Delta \mathrm{c}) \vee(\diamond \mathrm{b} \wedge \backslash \mathrm{c}) \\
& \wedge \neg(\diamond \mathrm{a} \wedge \diamond \mathrm{b} \wedge \triangleright \mathrm{c})
\end{aligned}
$$

$$
\begin{gathered}
(\text { un oarecare }) \\
(=\text { PARTIAL VARIATION }) \\
(=\text { ANTI-TOTAL VARIATION })
\end{gathered}
$$

The meaning we get for a model with three alternatives is that at least two alternatives are true in some world, but no more than two are (they cannot all be true). The formula in (76) entails that one of the alternatives is false, although we don't know

\begin{tabular}{|c|c|c|}
\hline \multicolumn{3}{|c|}{ a. Falsifying models for vreun } \\
\hline M1 & & \\
\hline w1 a & w1 & $\mathrm{a}$ \\
\hline w2 a & w2 & $\mathrm{b}$ \\
\hline w3 a & w3 & $\mathrm{c}$ \\
\hline
\end{tabular}
which one. For this to hold, more than one alternative has to be possible, thus excluding models where there is no variation (M1). In addition, vreun rules out total variation models (M2) and requires that at least one of the alternatives fail to be true. So (76) is only satisfied in partial variation models like M3 and M4 below.

b. Verifying models for vreun
$\begin{array}{cccc}\text { M3 } & \text { M4 } \\ \text { w1 } & \text { a } & \text { w1 } & \text { b } \\ \text { w2 } & \text { a } & \text { w2 } & \text { c } \\ \text { w3 } & \text { b } & \text { w3 } & \text { c }\end{array}$

This provides the first building block of our account of the epistemic constraint: the meaning of vreun encodes an anti-total variation requirement. This can be obtained on the assumption that vreun activates a richer set of alternatives, which includes its scalemate, the total variation indefinite un oarecare. To see how the anti-total variation condition derives the exclusion of vreun from deontic (and related nonepistemic) contexts, we now turn to the second ingredient of my analysis, which concerns the meaning of the modal operators interacting with vreun.

\subsubsection{Modals and free choice inferences}

In line with the alternative-based approach pursued here, we expect the narrower distribution of vreun in modal contexts, i.e. its exclusion from non-epistemic contexts, to fall out of the interaction between its active alternatives and the lexical semantics of the modal operators in the local structure. The remaining question is how to obtain the desired difference between epistemic and deontic (bouletic, and more generally priority modals) to which vreun seems to be sensitive. In the following, I argue that non-epistemic modals have, in a sense to be explained shortly, a strong free choice potential. To make this hypothesis more precise, we will proceed in two steps. First, we adopt the semantics of modalities in Aloni (2007) and derive the fact that vreun is ruled out in imperatives (a fact already illustrated in example (11)). Next, we extend this account to modal auxiliaries and consider various empirical facts to substantiate the claim that deontics, but not epistemics, have a strong free choice character. Building on the observed differences between the two kinds of modals, I derive the restriction of vreun to epistemic contexts from a clash between the conjectured antitotal variation requirement and the free choice semantics of deontic modals.

We begin by presenting the analysis in Aloni (2007), focusing on the two aspects that are directly relevant for the present account. First, disjunctions and 
indefinites are assumed to have two different representations: a regular and an alternative-inducing one, as given in (78a-b):

(78) a. Non-alternative-inducing representation:

$$
\exists x \mathrm{~A}(x) \quad \operatorname{ALT}=\{\exists x \mathrm{~A}(x)\}
$$

b. Alternative-inducing representation

$$
\exists p(p \wedge \exists x(\mathrm{p}=\mathrm{A}(x))) \quad \mathrm{ALT}=\left\{\mathrm{A}\left(d_{1}\right), \ldots, \mathrm{A}\left(d_{\mathrm{n}}\right)\right\}
$$

Truth-conditionally, the two representations are equivalent (and amount to existential quantification), but only the latter introduces genuine sets of alternatives (closely related to our domain alternatives). Dependent indefinites, like irgendein or vreun, always use alternative-inducing representations, i.e. their interpretation always associates with a set of alternatives.

A second key assumption is that modals and imperatives are alternativesensitive operators (in the spirit of e.g. Kratzer and Shimoyama 2002, MenéndezBenito 2005), a property that renders them analogous to the exhaustification operators employed by the present framework. More concretely, modals operate over (propositional) alternatives generated in their scope and entail that all alternatives should be compatible with the relevant modal base, i.e. each member of the alternative set should be possible, as in (79): ${ }^{39}$

(79) a. $\checkmark \phi$ is true iff every alternative induced by $\phi$ is compatible with the modal base

b. $\square \phi$ is true iff every alternative induced by $\phi$ is compatible with the modal base and at least one alternative induced by $\phi$ is entailed by the modal base

If the modal operator applies to the alternative-activating representation of an existential (78b), it gives rise to free choice effects, whereby each member of the alternative set is possible (80a). If on the other hand, it applies to the regular representation in (78a), no free choice effects are generated. This latter option yields the reading in ( $80 \mathrm{~b})$, which can be brought out by adding '... but I don't know which':

(80) You may have ice cream or cake.

a. $\diamond$ have ice cream $\wedge \diamond$ have cake

b. $\diamond$ (have ice cream $\vee$ have cake)

Let us now see how this proposal can help capture the behavior of alternativeactivating indefinites in imperatives:

\footnotetext{
39 The analysis in Aloni (2007) does not extend to necessity modals, for reasons pertaining to the distribution of any (see also fn. 24). However, as mentioned in Aloni and Franke (2013), the properties of any are derived differently in Chierchia (2013a), and consequently, once we allow for modals to operate over alternatives, nothing prevents the definition of an alternative-sensitive necessity modal.
} 


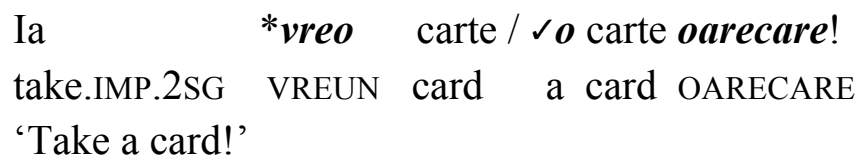

On Aloni's account, imperatives have a semantics close to necessity modals, with a free choice component built into their meaning, as in (82):

(82) Imperative ! $\phi$ is true in $w$ iff

(i) every alternative induced by $\phi$ is compatible with the modal base

(ii) the union of all these alternatives is entailed by the modal base

Applying this analysis to imperatives with alternative-activating indefinites such as those in (81) and assuming a domain with three elements, this amounts to the interpretation in (83):

$\square\left[\right.$ pick $\operatorname{card}_{1} \vee$ pick $\operatorname{card}_{2} \vee$ pick $\left.\operatorname{card}_{3}\right] \wedge \diamond$ pick $\operatorname{card}_{1} \wedge \diamond$ pick $\operatorname{card}_{2} \wedge \diamond$ pick $\operatorname{card}_{3}$

In other words, in each of the worlds compatible with the speaker's desires (goals, etc.), one of the three cards in the relevant domain gets picked. According to clause (i) above, each card is a possible way to comply with the request (order, suggestion, etc.) expressed by the imperative. The resulting free choice effect is compatible with a total variation indefinite like un oarecare, but clashes with the meaning of vreun proposed in section 4.3.1. More precisely, with the anti-total variation constraint built into the semantics of vreun, represented in (84):

a. Anti-Total Variation with possibility modals

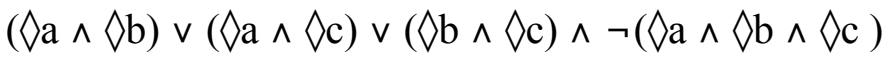

b. Anti-Total Variation with necessity modals

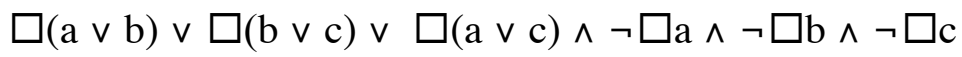

We have already shown how anti-total variation is derived under possibility modals, in (76) above. The formula in (84b) spells out the ban on total variation with necessity modals (which I must leave to the reader to compute) ${ }^{40}$ at least two alternatives must be true, but no single one is necessarily true. These formulae are only satisfied in models where one of the alternatives fails to hold, such as M3 or M4 in (85), repeated from above:

\begin{tabular}{|c|c|c|}
\hline \multicolumn{3}{|c|}{ a. Falsifying models for vreun } \\
\hline M1 & & \\
\hline w1 a & w1 & $\mathrm{a}$ \\
\hline w2 a & w2 & $b$ \\
\hline w3 a & w3 & $\mathrm{c}$ \\
\hline
\end{tabular}

b. Verifying models for vreun
$\begin{array}{llll}\text { M3 } & \text { M4 } \\ \text { w1 } & \text { a } & \text { w1 } & \text { b } \\ \text { w2 } & \text { a } & \text { w2 } & \text { c } \\ \text { w3 } & \text { b } & \text { w3 } & \text { c }\end{array}$


On this proposal, the deviance of vreun in (81) results from two conflicting requirements: the interpretation of the imperative, given in (83), only satisfied in a total variation model (M2), and the meaning of vreun, which is incompatible with total variation. The only modification introduced in the system is that we allow modals to operate directly over alternatives, a move that is compatible with the present framework (see Chierchia 2013a, p. 359 for further discussion). Although we cannot properly address the details of Aloni's proposal, the predictions of this line of analysis should be clear: free choice effects are the result of the interplay between (i) an existential element with an alternative-triggering representation (78b) and (ii) a modal alternative-sensitive operator (with the semantics in (79) or (82)). If one of the two ingredients is missing, no free choice interpretation arises. ${ }^{41}$

The analysis just sketched gets us one step closer to deriving the restriction of vreun to epistemic contexts. More specifically, extending this approach, I submit that deontic (and other priority) modals, but not epistemics, behave like imperatives, i.e. they induce a free choice, total variation reading of alternative-activating existentials in their scope. Just like with imperatives then, this property clashes with the conjectured 'anti-total variation' meaning of vreun. I will make a case that such a distinction among modals is, on the one hand, plausible in view of how they affect alternatives in their scope and, on the other hand, independently needed to capture other phenomena that seem sensitive to this split. If the proposal is on the right track, we explain the epistemic constraint to which vreun is subject.

There are a number of empirical observations supporting the claim that certain modals have a stronger free choice character. In the following, we will concentrate on the contrast between deontic and epistemic modals, but similar considerations arguably apply to other non-epistemic modalities and attitude predicates (for bouletics, see Chierchia 2013a, pp. 264-267). Both deontic and epistemic modals can trigger free choice effects on disjunction (and existentials) in their scope. In uttering something like You may eat the cake or the ice cream (with unstressed or), we typically convey that both eating the cake and eating the ice cream are allowable options. This is precisely the reason why a sequence like You may eat the cake or the ice cream; in fact you may only eat the cake is perceived as contradictory. If permission holds for the initial set of options (which includes the cake and the ice

\footnotetext{
${ }^{40}$ For a full derivation of anti-total variation under necessity modals, see Chierchia (2013a, p. 299).

${ }^{41}$ This leaves open the possibility that if, for some reason, the modal/imperative operator does not have the free choice-inducing semantics in $(79) /(82)$, vreun becomes acceptable. This prediction is borne out. Fălăuş (2012) shows that vreun is acceptable in (roughly) those imperatives where English would use some, e.g. Talk to some neighbor (they might be able to help)! I can see two ways to accommodate this observation. The first is to follow Aloni and argue that these imperatives do not induce total variation (they are so-called 'alternative-presenting' imperatives), i.e. they have a way of satisfying the anti-total variation constraint (as suggested in Fălăuş 2012). Another option is to maintain the semantics in (82) for imperatives, but assume that there is a second modal present in their structure, which weakens the free choice semantics of the imperative. This second strategy is in line with recent analyses of imperatives (e.g. Kaufmann 2012) and is independently argued for in Dayal (2013), which shows the need for a more fine-grained understanding of the interaction between imperatives and free
} 
cream), then it must also hold for each of its subsets, i.e. each of the disjuncts. Likewise with epistemic modals, e.g. John might be in Paris or in Barcelona can give rise to the inference that he might be in any of the two cities. However, upon closer scrutiny, there are interesting differences between these two kinds of modalities, which suggest that free choice inferences are more readily available in deontic contexts. To see this, let us consider the interaction between modals and indefinites.

One supporting empirical observation comes from their behavior with respect to implicit exceptions, which are perfectly compatible with epistemics, but not with deontics. Consider (86):

a. John must/may go to one of the rooms upstairs.

b. John must/might be in one of the rooms upstairs.

The sentence in (86a), with a deontic modal, either conveys that John must/may go to a specific room, or if not, his obligation/permission is satisfied by going to any one of the rooms in the context. Unless specified otherwise, any room in the relevant domain should be a way of complying. If it turns out that John went to, say, my bedroom, it would be odd to complain by uttering something like Oh wait, I didn't mean this room. Any exception should be explicitly ruled out. ${ }^{42}$ The epistemic statement in (86b) is compatible with a wider variety of situations. Just like with the deontic, the modal claim could be about a specific room, or could apply to any room. Crucially however, it could also apply to any subset of the relevant rooms, like in the hide-andseek scenario we used in (63), where not all rooms are possible options. Nothing forces the free choice inference, unlike what we observe with the deontic modal. ${ }^{43}$

A similar point can be made by considering cases where we clearly restrict the freedom of choice, i.e. we exclude one of the possible alternatives. Once again, a different pattern emerges in deontic and epistemic cases: whereas epistemics are compatible with such set-ups, deontics are not. For example, suppose we are playing a game consisting of negotiating moves with an oracle that answers queries and gives instructions. If the oracle knows that the treasure is in Room A, and therefore Room B is not a real option, it could still felicitously utter (87a). In contrast to this, the oracle

choice elements like any. A proper discussion of this complex issue would take us too far afield from the main purposes of this paper.

${ }^{42}$ As suggested by an anonymous referee, the free choice induced on existentials under deontic modals may have to do with their function to restrict, or in the case of possibility operators, to un-restrict options. If a possible value is not explicitly excluded, the deontic operator rules it in.

43 Alonso-Ovalle and Menéndez-Benito (2013) dispute the claim that deontic modals trigger free choice on the basis of examples like the following, where they take exceptives to indicate that the indefinite phrase does not refer to the entire set of cards (i.e. we have a partial variation context):

(i) You can take a card, except for this one/but it can't be any of the aces.

Note however that exceptives are compatible with both partial variation (e.g. algún or vreun in (63)) and total variation determiners. For example, they are compatible with universals or free choice indefinites Take every/any card, except this one (see von Fintel 1993) and with total variation indefinites like un oarecare/un qualsiasi (Chierchia 2013a, p. 268). As a result, exceptives do not provide a reliable test for the strength of free choice inferences. 
could not say (87b) knowing that Room B is not an option, because, say, it is locked (it would have to say 'you may try to go into Room A or Room B'):

(87) a. The treasure might be in Room A or in Room B.

b. You may go into Room A or Room B.

I take these facts as indicating that deontic modals with alternative-activating elements in their scope have a stronger free choice flavor, i.e. they give rise to a total variation inference. The wider range of interpretations observed with epistemic operators shows that they do not impose such a requirement, although they are of course compatible with total variation set-ups.

Further evidence in favor of the claim that deontics and epistemics can trigger different effects on embedded alternatives comes from so-called universal free choice inferences, recently discussed in Aloni and Franke (2013). It has been observed that free choice inferences associated with disjunction under deontic modals take scope under universal quantifiers (Chemla 2009). For example, the sentence in (88a) supports the free choice inference in (88b):

a. Every student may take semantics or pragmatics.

b. Every student may take semantics and every student may take pragmatics.

Crucially, this effect seems to depend on the kind of modality involved. Van Tiel (2011) provides experimental evidence suggesting that the inference in (88) is significantly stronger than the one in (89), with an epistemic modal: ${ }^{44}$

(89) a. According to the professor, every research question might be answered by a survey or an experiment.

b. According to the professor, every research question might be answered by a survey, and, according to the professor, every research question might be answered by an experiment.

Universal free choice inferences are possible with epistemic modals, but they are less prominent than with deontic modals. This once again suggests that deontics and epistemics induce different effects on alternatives in their scope.

The data considered here lead to the conclusion that alternative-activating elements can acquire different interpretations in epistemic and deontic contexts, corroborating the observation made for vreun. Furthermore, the sensitivity of vreun to different types of modality fits in with other recent studies showing similar differences in other domains. For example, Aloni and Port (2010) observe that irgendein gives rise to different inferences under the two kinds of modals: total variation in deontic contexts and partial variation in epistemic ones (see also Lauer

\footnotetext{
${ }^{44}$ The use of 'according to the professor' is meant to facilitate the epistemic reading of the modal, which is otherwise not very prominent.
} 
(2010)). This suggests a strong correlation between deontic modals and total variation. Moreover, Crnič (2011) shows that concessive scalar particles like Slovenian magari are licensed under deontic modals but not under epistemic ones. Interestingly, both studies provide explanations that rely on free choice inferences being different in deontic and epistemic contexts. To this, we may add the behavior of supplementary any (e.g. Dayal 2004): while with epistemic necessity modals supplementary any is infelicitous, with deontics not only is it felicitous, but seems emphatic or even redundant.

a. \# John must be with a friend, any friend.

b. John must come with a friend, any friend.

These facts provide converging evidence that deontics and epistemics have a different impact on alternative-activating elements. The differences, manifested in various constructions, should follow from the semantics of the modal operators, as we have tried to indicate here. The precise implementation of the distinction in free choice potential is at this point an open issue. The strategy pursued here consists in building this property into the meaning of deontic operators, along the lines of Aloni (2007). ${ }^{45}$ In a recent study, which to my knowledge is the only formally explicit attempt to tackle this problem, Aloni and Franke (2013) explore a pragmatic account. The gist of their proposal is that the observed differences can be explained in terms of pragmatic relevance. More precisely, they contrast situations in which deontic and epistemic universal free choice inferences (e.g. (88)-(89)) do or do not arise. They argue that such inferences are more relevant for practical purposes, i.e. for choosing a course of action, in deontic than in epistemic contexts. ${ }^{46}$ As a result, free choice effects are

\footnotetext{
${ }^{45}$ There are several other possible ways to formally capture the free choice character of deontics on a semantic account. A weaker version of the idea sketched in the text is to maintain a standard (nonalternative-sensitive) meaning for modals and assume that the free choice component is a presupposition of deontic modals, as spelled out in (i):

(i) $\square_{\text {DEONTIC }}(\phi)$ is defined iff for every $\left.\mathrm{p} \in \operatorname{ALT}(\phi),\right\rangle_{\text {DEONTIC }} \mathrm{p}$

This has the effect of requiring that each alternative be true in some world of the modal base. If there are no active alternatives, this has no effect. But in the presence of an alternative-triggering element, this induces free choice effects. The anti-total variation meaning of vreun clashes with the free choice presupposition in (i), hence its deviance in deontic contexts.

Chierchia (2013a, p. 266) suggests a solution that consists in assuming the following meaning postulate (for deontics and imperatives):

(ii) $\square_{\mathrm{FC}}\left[\exists x \in \mathrm{D}[\mathrm{P}(x)] \rightarrow \forall \mathrm{D}^{\prime} \subseteq \mathrm{D} \diamond_{\mathrm{FC}} \exists x \in \mathrm{D}^{\prime}[\mathrm{P}(x)]\right.$

To make this work, modals would need to be treated as alternative-sensitive operators. As formulated right now, this postulate looks at 'standard' meaning, leaving it unclear how it deals with the difference between alternative-activating and non-alternative-activating elements.

More work is clearly needed to test the predictions of the various conceivable implementations and distinguish between these options.

${ }^{46}$ Aloni and Franke relate this difference to the fact that deontic and epistemic statements convey different types of information. Intuitively, epistemic information has to do with compatibility between pieces of information, without necessarily determining future courses of action. In contrast to this, deontic information is factual - it provides directly useful information about practically relevant permissions and obligations. This is formalized by adopting a dynamic account of epistemic modality (Veltman 1996, Yalcin 2007), combined with a classical relational approach to deontic modality. I refer to Aloni and Franke (2013) for further details.
} 
more readily and more frequently available with deontic operators. Over time, this effect can grammaticalize (via a process called 'pragmatic fossilization'), leading to differences in the extent to which these inferences infiltrate compositional semantics.

The present paper does not seek to distinguish between a semantic and a pragmatic explanation for the different free choice potential of modals. However, I would like to address an empirical issue that Aloni and Franke view as problematic for a semantic account that combines the proposal in Aloni (2007) and the framework in Chierchia (2013a), along the lines being considered here. They argue that once we build free choice into the meaning of deontics, we make wrong predictions concerning the behavior of partial variation indefinites like un qualche or algún. More precisely, if deontics always require free choice among alternatives in their scope, we expect all alternative-activating indefinites to give rise to total variation effects in deontic contexts. This does not seem to be the case for un qualche in (91), where the continuation specifies that not any kind of basic skill is enough:

(91) Per diventare traduttore devi avere un qualche tipo di base. Di sicuro devi saper leggere e in alcuni casi devi anche sapere scrivere.

'To become a translator you must have some basic skills. For sure you must be able to read and in some cases you must also know how to write.'

Alonso-Ovalle and Menéndez-Benito (2013) make a similar point concerning (92), where algún simply requires that there be at least two doctors that Mary can marry:

Mary se tiene que casar con algún médico.

'Mary has to marry some doctor or other.'

Without getting into a detailed discussion of the properties of un qualche/algún, there are two things worth pointing out in this connection. First, the facts are not entirely clear at this point. Note that Chierchia (2013a, p. 286) makes the opposite empirical claim, arguing that un qualche triggers total variation in examples such as those in (93), as confirmed by the infelicity of a continuation that seeks to deny this effect:

a. ?? Prendi una qualche carta, ma non puoi prendere una carta qualsiasi.

'Take some card or other, but you cannot take any old card.'

b.?? Per legge, devo avere una qualche assicurazione ma non un'assicurazione qualsiasi.

'By law, I must have some insurance or other, but not any insurance.'

Moreover, there may be an underlying confounding factor, namely the fact that $u n$ qualchelalgún can be used in deontic contexts where the elements in the quantificational domain are (possibly) unknown, hence the impression that the speaker does not intend her claim to apply to all elements in the domain. However, the possible ignorance concerning elements in the domain is in principle independent of total/partial variation. For example, imagine a situation where we are playing hide- 
and-seek in a house I don't know very well. If I utter (94), my claim applies to all rooms in the house (unless specified otherwise). Consequently, I wouldn't be entitled to say that you didn't follow the rules in case you hid in some secret room of the house I wasn't initially aware of:

Tienes que esconderte en alguna habitación de la casa.

'You must hide in a room of the house.'

If it turns out that an element is part of the quantificational domain, this element constitutes a viable way of complying with the obligation/permission expressed by the modal. Total variation in deontic contexts therefore holds even in the absence of knowledge concerning the range of options.

A second point I would like to make concerning these facts is that the alternative-based approach pursued here has ways to capture the absence of total variation of un qualche/algún in deontic contexts (if this turns out to be real). More concretely, we could assume that the LF of sentences such as (91)-(92) involves two modals, as schematized in (95): the deontic modal auxiliary and a covert assertoric (epistemic) modal (discussed in (59) above):

\section{$\square_{\mathrm{S}}\left[\right.$ un qualche/algún $\left.\square_{\text {DEONTIC }}\right]$}

In the absence of the null assertoric modal $\square_{\mathrm{S}}$, this structure is illicit: epistemic indefinites always take narrow scope with respect to the modal that 'licenses' them (for reasons explained in Chierchia 2013a, p. 258). The insertion of a covert modal rescues this configuration. ${ }^{47}$ This 'last resort' strategy might then explain the lack of total variation perceived in examples such as (91)-(92): the indefinite is not in the scope of a deontic operator. (92) simply says that Mary has to marry a doctor and the speaker does not know (or care) who that is, without imposing any constraints on whether some or all relevant doctors can satisfy the modal claim. A welcome consequence of this line of analysis is that the structure in (95) is not available for vreun, which we have shown to disallow the covert modality strategy (see the discussion in section 4.1). We therefore correctly predict that it can never occur in sentences such as (91): the only available LF is one in which vreun is in the scope of the deontic modal, which automatically generates a contradiction. If this option is available to the alternatives-and-exhaustification approach to deal with the possible absence of total variation effects with un qualche/algún, it would have a pay off in explaining the different behavior of vreun.

The conclusion emerging from our brief discussion of the properties of $u n$ qualche and algún is that the interaction between modalities and epistemic indefinites is a complex matter, still in need of empirical investigation. The crucial point for

\footnotetext{
${ }^{47}$ The availability of the covert modality strategy is confirmed by the acceptability of un qualche and algún in episodic sentences:

(i) Maria ha sposato un qualche dentista. 'Maria married some dentist or other.'
} 
present purposes is that there is a clear split in the way deontics and epistemics interact with alternative-activating elements. Regardless of how exactly this behavior is ultimately captured and formalized, I take the free choice character of deontic modals to provide a compelling explanation for the restriction of vreun to epistemic contexts. My account of the epistemic constraint makes use of two independent empirical observations. On the one hand, the anti-total variation inference, optional for indefinites like un qualche and algún, but obligatory with vreun (as spelled out in 4.3.1). On the other hand, the free choice character of deontics, supported by their interaction with alternative-activating elements and the differences with epistemic modals noted in this connection. If vreun is embedded under a modal that imposes no constraints on alternatives, the anti-total variation requirement can be satisfied. Under epistemic modals, then, things can go both ways. If nothing in the context imposes total variation (as we have seen to be usually the case with epistemics), ${ }^{48}$ vreun can be used. If on the other hand, we have a total variation epistemic set-up, vreun is ruled out. This is confirmed by the deviance of vreun in a total variation version of the hideand-seek scenario in (63) or in the shell game scenario in (71), which establishes that the ball could be in any one of the three boxes under consideration. Deontic modals do not have the same flexibility: they trigger free choice on embedded alternatives, which systematically clashes with the anti-total variation meaning of vreun. Hence its deviance. The only way out would be the insertion of a covert epistemic modal, a strategy that vreun disallows. The epistemic constraint thus neatly falls into place. The only item-specific property posited here is the anti-total variation requirement, triggered by the competition with the total variation indefinite un oarecare. This requirement aside, the (un)grammaticality of vreun is a direct consequence of the interplay between its alternative-triggering meaning and the semantic properties of the embedding operator, just like elsewhere in the polarity system.

\section{Conclusions}

This paper examined a puzzling case of polarity sensitivity, manifested by Romanian vreun, and argued that an alternative-based semantics makes possible a uniform account of its distribution. Our study reveals new parameters of variation among polarity sensitive indefinites (types of modality) and extends the alternative-andexhaustification framework by using a new type of alternatives for meaning enrichment (complex alternatives, resulting from competition with other members of the polarity system). More concretely, on the empirical side, the main outcome of our investigation is the systematic incompatibility between vreun and non-epistemic operators, captured by the epistemic constraint. Adopting the alternative-based theory developed in Chierchia (2013a), we analyzed vreun as an indefinite with obligatorily

\footnotetext{
48 There is an intuitive connection between the absence of constraints imposed on alternatives in their scope and the uncertainty/indirect evidentiality built into the meaning of epistemic operators. Recall that the modal base relevant for the interpretation of epistemics contains the worlds not ruled out by direct evidence, leaving open a large number of possibilities to satisfy the modal claim. Properly justified and worked out, this property of epistemic modals might explain why they allow for a wider range of interpretations of alternative-activating elements in their scope.
} 
active alternatives, which can only be consistently factored into meaning in the presence of a downward-entailing or modal operator. The deviance in non-epistemic contexts was argued to arise from two conflicting requirements: the ban on total variation encoded by vreun and the free choice component of deontic modals. To formally implement this proposal, we hypothesized that vreun activates a richer set of alternatives: in addition to scalar and singleton domain alternatives, common to all partial variation indefinites, it also includes the 'complex' alternatives brought about by the competition with un oarecare. This account opens up the possibility that the set of active alternatives associated with a polarity sensitive indefinite includes not only grammatically determined alternatives (lexically activated or derived via recursive exhaustification), but also other alternative-activating elements in the polarity system.

I would like to conclude this discussion by briefly mentioning some open questions and directions for future research. First, to extend the empirical coverage of this account, we need to carefully check its predictions for other intensional contexts. This involves a detailed examination of the interaction with other non-epistemic modals (e.g. bouletics) and with attitude predicates, whose semantics and embedding properties constitute a complex area of investigation in Romanian (e.g. Braşoveanu 2006, Braşoveanu and Farkas 2007, Anand and Hacquard 2013). The use of vreun in certain imperfective contexts (mentioned in section 1.2) indicates that aspectual properties may also have a role in satisfying the anti-total variation requirement. A further open issue is the role of presuppositions in the (un)acceptability of vreun. Its exclusion under factive predicates such as know/find out (noted in (28)) suggests that epistemic indefinites may be sensitive not only to truth-conditional aspects of meaning (as in all the cases we have considered here), but also presuppositions. ${ }^{49} \mathrm{~A}$ full account would also make a close comparison between the vreun studied here and partitive vreun, since its definite inner noun phrase provides an important control. Whatever further empirical properties of vreun will be uncovered, ideally, they should follow from the interaction between its lexical meaning and the regular semantics of the operators in the context.

The properties of vreun discussed in this paper contribute to our knowledge of dimensions of variation among semantically dependent indefinites, and as such pave the way to a principled explanation for the attested diversity. We have shown how to capture this pattern into a tightly regulated parametric system of polarity, preserving the insight in Farkas $(2002,2006)$ that alternatives are the key to understanding the behavior of vreun. In explaining its distributional restrictions, we made use of independent properties of the operators with which vreun interacts, thus eliminating traditional licensing constraints. The outcome is an account where labeling vreun a negative polarity item or an epistemic indefinite amounts to nothing more than a

\footnotetext{
49 The proposal that polarity items may be sensitive to different meaning components has been put forward in Gajewski (2011) and adopted in Chierchia (2013a) to explain the ungrammaticality of strong NPIs in the scope of presuppositional operators such as only. More concretely, weak NPIs like ever are argued to be sensitive to just the truth-conditional component of their licensors, while strong NPIs like in weeks are sensitive also to the presuppositions and implicatures. It would therefore be interesting to find a parallel split among epistemic indefinites.
} 
terminological move. The proposal makes clear predictions and offers tools to explore other contexts and tackle other potentially relevant factors, like presuppositional aspects of meaning or the interaction with temporal and aspectual operators. I leave these remaining issues for future research, but I hope to have shown that the present approach provides insightful ways to address them.

\section{Acknowledgements}

This paper grew out of my dissertation (Fălăuş 2009). I am greatly indebted to Hamida Demirdache and Gennaro Chierchia for inspiration, guidance and invaluable feedback all throughout this project. Special thanks to Donka Farkas, whose work and suggestions very much influenced my thinking about Romanian indefinites, and to Orin Percus, who provided insightful comments on an earlier version of the analysis. For helpful discussion, I also wish to thank all of my informants, as well as Maria Aloni, Luis Alonso-Ovalle, Ivano Caponigro, Carmen Dobrovie-Sorin, Anastasia Giannakidou, Brenda Laca, Paula Menéndez-Benito, Lucia Tovena and Hedde Zeijlstra. Previous versions of this paper have been presented at IGG 36 in Milan, LSRL 40 in Seattle, SALT 20 in Vancouver, the Workshop on Epistemic Indefinites in Göttingen, Institut Jean Nicod, University of Paris 7, University of Paris 8, Institute for Logic, Language and Computation at the University of Amsterdam, Leiden University, Harvard University and UC San Diego. I thank the audiences for their questions and comments. I am also very grateful to Veneeta Dayal and three anonymous Linguistics and Philosophy reviewers for their detailed comments and suggestions, which greatly improved the final version of this paper. All errors and omissions are mine.

This research was partially funded by the Laboratoire de Linguistique de Nantes (LLING EA 3827), the Spanish Ministry of Science and Innovation (FFI2011-29218), the Basque Government (IT-769-13) and the University of the Basque Country UPV/EHU (UFI11/14).

\section{References}

Aloni, Maria. (2007). Free choice, modals and imperatives. Natural Language Semantics 15: 65-94.

Aloni, Maria and Robert van Rooij. (2007). Free choice items and alternatives. In Proceedings of the KNAW Academy Colloquium: Cognitive Foundations of Interpretation, G. Bouma, I. Kraemer, and J. Zwarts (eds.), pp. 5-26.

Aloni, Maria and Angelika Port. (2010). Epistemic indefinites crosslinguistically. In Proceedings of NELS 41.

Aloni, Maria and Michael Franke. (2013). On the free choice potential of epistemic and deontic modals. In From Grammar to Meaning: The Spontaneous Logicality of Language, I. Caponigro and C. Cecchetto (eds.). Cambridge University Press.

Alonso-Ovalle, Luis. (2005). Distributing the disjuncts over the modal space. In Proceedings of the North East Linguistic Society 35 GLSA, L. Baterman and C. Ussery (eds.), pp. 1-12. Amherst, MA.

Alonso-Ovalle, Luis and Paula Menéndez-Benito. (2008). Minimal domain widening. In Proceedings of the 27th West Coast Conference on Formal Linguistics, N. 
Abner and J. Bishop (eds.), pp. 36-44. Somerville, MA: Cascadilla Proceedings Project.

Alonso-Ovalle, Luis and Paula Menéndez-Benito. (2010). Modal indefinites. Natural Language Semantics 18(1): 1-31.

Alonso-Ovalle, Luis and Paula Menéndez-Benito (2013). Two views on epistemic indefinites, Language and Linguistics Compass 7/2: 105-122.

Anand, Pranav and Valentine Hacquard. (2013). Epistemics and attitudes. Semantics and Pragmatics 6.8: 1-59

Braşoveanu, Adrian. (2006). Temporal and propositional De Se: evidence from Romanian Subjunctive Mood. In Proceedings of Sinn und Bedeutung 10: 55-70.

Braşoveanu, Adrian and Donka Farkas. (2007). Say reports, assertion events and meaning dimensions. In Pitar Moș: A Building with a View. Papers in Honour of Alexandra Cornilescu, G. Alboiu, A. Avram, L. Avram and D. Isac (eds.), Bucharest: Editura Universității din București.

Chemla, Emmanuel. (2009). Universal implicatures and free choice effects: experimental data. Semantics and Pragmatics 2: 1-33.

Chierchia, Gennaro. (2006). Broaden your views. Implicatures of domain widening and the spontaneous logicality of language. Linguistic Inquiry 37(4): 535-590.

Chierchia, Gennaro. (2013a). Logic in Grammar: polarity, free choice and intervention. Oxford University Press.

Chierchia, Gennaro. (2013b). FC nominals and FC disjunction: the identity thesis. In Alternatives in Semantics, A. Fălăuş (ed.), Palgrave Macmillan.

Chierchia, Gennaro, Danny Fox and Benjamin Spector. (2012). The grammatical view of scalar implicatures and the relationship between semantics and pragmatics. In Semantics: An International Handbook of Natural Language Meaning, C. Maienborn, K. von Heusinger, and P. Portner (eds). Berlin: Mouton de Gruyter.

Condoravdi, Cleo. (2005). Not knowing or caring who, manuscript, PARC and Stanford University.

Crnič, Luka. (2011). Getting even. Ph.D. dissertation. MIT

Dayal, Veneeta. (1997). Free relatives and ever: identity and free choice readings. In Proceedings of SALT VII, A. Lawson (ed.), pp. 99-116, Ithaca, NY: Cornell University.

Dayal, Veneeta. (1998). Any as inherently modal. Linguistics and Philosophy 21: 433-476.

Dayal, Veneeta. (2004). The universal force of free choice any. Linguistic Variation Yearbook 4.1: 5-40.

Dayal, Veneeta. (2009). Variation in English free choice items. In Universals and Variation: Proceedings of GLOW in Asia VII, R. Mohanty and M. Menon, (eds.), pp. 237-256.

Dayal, Veneeta. (2013). A viability constraint on alternatives for free choice. In Alternatives in Semantics, A. Fălăuş (ed.), Palgrave Macmillan.

Farkas, Donka. (2002). Extreme non-specificity in Romanian. In Romance Languages and Linguistic Theory 2000, C. Beyssade et al. (eds.), pp. 127-153, Amsterdam: John Benjamins.

Farkas, Donka. (2006). Free choice in Romanian. In Drawing the Boundaries of Meaning, B. Birner and G. Ward (eds.), pp. 71-94. Amsterdam: John Benjamins.

Fauconnier, Gilles. (1975) Pragmatic Scales and Logical Structure. Linguistic Inquiry, 6:353-375.

Fălăuş, Anamaria. (2009). Polarity items and dependent indefinites in Romanian, Ph.D dissertation, University of Nantes. 
Fălăuş, Anamaria. (2010). Alternatives as sources of semantic dependency. In Proceedings of SALT 20, N. Li and D. Lutz (eds.), pp. 406-427. eLanguage.

Fălăuş, Anamaria. (2012). On alternatives in imperatives: the case of Romanian vreun. In Proceedings of Sinn und Bedeutung 16, A. Aguilar, A. Chernilovskaya, and R. Nouwen (eds.), pp. 239-252.

Fălăuş, Anamaria. (2013). Introduction: alternatives in semantics and pragmatics. In Alternatives in Semantics, A. Fălăuş (ed.), Palgrave Macmillan.

Fălăuş, Anamaria. to appear. Romanian Epistemic Indefinites. In Epistemic indefinites, L. Alonso-Ovalle and P. Menéndez-Benito (eds.), Oxford University Press.

von Fintel, Kai. (1993). Exceptive constructions. Natural Language Semantics 1: $123-48$.

von Fintel, Kai. (1999). NPI-Licensing, Strawson-Entailment, and Context Dependency. Journal of Semantics 16: 97-148.

von Fintel, Kai. (2000). Whatever. In Proceedings from Semantics and Linguistic Theory (SALT 10), B. Jackson and T. Matthews (eds.), pp. 27-39. Ithaca, NY: Cornell University.

von Fintel, Kai and Anthony Gillies. (2010). Must...stay...strong!. Natural Language Semantics: 18(4): 353-381

Fox, Danny. (2007). Free choice disjunction and the theory of scalar implicatures. In Presupposition and Implicature in Compositional Semantics, U. Sauerland and P. Stateva (eds.), pp. 71-120. New York: Palgrave Macmillan.

Gajewski, Jon. (2002). L-Analyticity and natural language, manuscript, MIT.

Gajewski, Jon. (2011). Licensing strong NPIs. Natural Language Semantics 19:10948.

Giannakidou, Anastasia. (1997). The landscape of polarity items, Ph.D. Dissertation, University of Groningen.

Giannakidou, Anastasia. (2011). Negative and positive polarity items: licensing, compositionality and variation. In Semantics: An International Handbook of Natural Language Meaning, C. Maienborn, K. von Heusinger, and P. Portner (eds). Berlin: Mouton de Gruyter.

Giannakidou, Anastasia and Josep Quer. (2011). Free choice and referential vagueness in Spanish, Catalan and Greek. manuscript

Guerzoni, Elena, and Yael Sharvit. (2007). A question of strength: on NPIs in interrogative clauses. Linguistics and Philosophy 30:361-391.

Hacquard, Valentine. (2006). Aspects of modality. Ph.D. Dissertation. MIT.

Haspelmath, Martin. (1997). Indefinite pronouns. Oxford: Oxford University Press.

Heim, Irene. (1992). Presupposition projection and the semantics of attitude verbs. Journal of Semantics 9: 183-221.

Hoeksema, Jack. (1999). Blocking effects in the expression of negation. Leuvense Bijdragen/Leuven Contributions in Linguistics and Philology, 88-3/4: 403-423.

Horn, Laurence (2001). A natural history of negation. $2^{\text {nd }}$ ed. University of Chicago Press.

Irimia, Monica. (2010). Some remarks on the evidential nature of the Romanian presumptive. In Romance Languages and Linguistic Theory 2008, R. BokBennema, B. Kampers-Manhe and B. Hollebrandse (eds.),pp. 125-144. Amsterdam: John Benjamins.

Iordăchioaia, Gianina. (2009). Negative concord with negative quantifiers: A polyadic quantifier approach to Romanian negative concord. Ph.D dissertation, University of Tübingen. 
Jayez, Jacques and Lucia Tovena. (2006). Epistemic determiners. Journal of Semantics 23, 217-250.

Jayez, Jacques and Lucia Tovena. (2007). Evidentiality and determination. In Proceedings of Sinn und Bedeutung 12: 271-286.

Kadmon, Nirit and Fred Landman. (1993). Any. Linguistics and Philosophy 16: 353422.

Kaufmann, Magdalena. (2012). Interpreting imperatives. New York: Springer.

Kratzer, Angelika (1981). The notional category of modality. In Words, Worlds, and Context, H. Eikmeyer and H. Rieser (eds). Berlin: De Gruyter.

Kratzer, Angelika. (1991). Modality. In Semantics: An International Handbook of Contemporary Research, A. von Stechow and D. Wunderlich (eds.), pp. 639650. Berlin: De Gruyter.

Kratzer, Angelika. (2005). Indefinites and the operators they depend on: from Japanese to Salish. In Reference and Quantification. The Partee Effect, G. Carlson and F. Jeffry Pelletier (eds.), pp. 113-142. Stanford, CA: CSLI Publications.

Kratzer, Angelika and Junko Shimoyama. (2002). Indeterminate pronouns: the view from Japanese. In Proceedings of the Third Tokyo Conference on Psycholinguistics, Y. Otso (ed.). Tokyo: Hituzi Syobo.

Krifka, Manfred. (1995). The semantics and pragmatics of polarity items. Linguistic Analysis 25: 209-257.

Krifka, Manfred. (2006). Association with focus phrases. In The architecture of focus, V. Molnar and Susanne Winkler (eds.), pp. 105-136. Berlin: Mouton de Gruyter.

Ladusaw, William. (1979). Polarity sensitivity as inherent scope relations. Ph.D dissertation, University of Texas at Austin, reproduced by the IULC, 1980.

Lahiri, Utpal. (1998). Focus and negative polarity in Hindi. Natural Language Semantics 6: 57-123.

Lauer, Sven. (2010). Some news on irgendein and algún. Paper presented at the Workshop on Epistemic Indefinites, Göttingen, June 2010.

Linebarger, Marcia (1980). The grammar of negative polarity. Ph.D. dissertation, MIT.

Matthewson, Lisa, Hotze Rullmann and Henry Davis. (2007). Evidentials as epistemic modals: evidence from St'át'imcets. In Linguistic Variation Yearbook 7: 201254.

Menéndez-Benito, Paula. (2005). The grammar of choice. Ph.D dissertation, University of Massachusetts, Amherst.

Nicolae, Andreea. (2013). Any questions? Polarity as a window into the structure of questions. $\mathrm{PhD}$ dissertation, Harvard University

Pereltsvaig, Asya. (2004). Negative polarity items in Russian and the "Bagel Problem". In Negation in Slavic, A. Przepiorkowski and S. Brown (eds.). Bloomington: Slavica Publishers.

Rawlins, Kyle. (2008) (Un)Conditionals: an Investigation in the Syntax and Semantics of Conditional Structures, PhD dissertation, UCSC.

van Rooij, Robert and Kathrin Schulz. (2006). Pragmatic meaning and non-monotonic reasoning: the case of exhaustive interpretation. Linguistics and Philosophy 29(2): 205-250.

Rooth, Mats. (1985). Association with Focus. Ph.D. dissertation, University of Massachusetts, Amherst.

Rooth, Mats. (1992). A theory of focus interpretation. Natural Language Semantics 1: 75-116. 
Sauerland, Uli. (2004). Scalar implicatures in complex sentences. Linguistics and Philosophy 27:367-391.

Săvescu-Ciucivara, Oana. (2007). Oarecare indefinites are not just any indefinites. In Pitar Moș: A Building with a View. Papers in Honour of Alexandra Cornilescu, G. Alboiu, A. Avram, L. Avram and D. Isac (eds.), pp. 205-225, Bucharest: Editura Universității din București.

Scheffler, Tatjana. (2008). Semantic operators in different dimensions, Ph.D. dissertation, UPenn.

van Tiel, Bob. (2011). Universal free choice?. In Proceedings of Sinn und Bedeutung 16, A. Aguilar, A. Chernilovskaya and R. Nouwen (eds.), pp. 627638.

Veltman, Frank. (1996). Defaults in update semantics. Journal of Philosophical Logic 25: 22-261.

Vendler, Zeno. (1967). Each and every, any and all. Linguistics in Philosophy. Ithaca: Cornell University Press.

Yalcin, Seth. (2007). Epistemic modals. Mind 116: 983-1026.

Zamparelli, Roberto. (2007). On singular existential quantifiers in Italian. In Existence: Semantics and Syntax, I. Comorovski and K. von Heusinger (eds.), pp. 293-328. Springer.

Zwarts, Frans. (1998). Three Types of Polarity. In Plural Quantification, F. Hamm and E. Hinrichs (eds.).Dordrecht: Kluwer. 